\title{
Carboxyl-rich coatings deposited by atmospheric plasma co-polymerization of maleic anhydride and acetylene
}

\author{
Anton Manakhov $^{\mathrm{a}}{ }^{*}$, Miroslav Michlíček $^{\mathrm{b}}$, David Nečas ${ }^{\mathrm{a}, \mathrm{b}}$, Josef Polčák $^{\mathrm{c}}$, Ekaterina \\ Makhneva ${ }^{\mathrm{a}, \mathrm{d}}$, Marek Eliáśs ${ }^{\mathrm{a}, \mathrm{b}}$, Lenka Zajíčkováa,b
}
${ }^{\text {a }}$ Plasma Technologies, CEITEC - Central European Institute of Technology, Masaryk University, Kotlářská, 2, Brno 61137, Czech Republic

${ }^{\mathrm{b}}$ Department of Physical Electronics, Faculty of Science, Masaryk University, Kotlářská 2, Brno 61137, Czech Republic
${ }^{c}$ CEITEC - Central European Institute of Technology, Brno University of Technology, Technická 3058/10, 61600 Brno, Czech Republic.

${ }^{\mathrm{d}}$ Department of Condensed Matter Physics, Faculty of Science, Masaryk University, Kotlářská 2, Brno 61137, Czech Republic

Corresponding author : Dr. Anton Manakhov,

Plasma Technologies, CEITEC - Central European Institute of Technology, Masaryk

University, Kotlářská, 2, Brno 61137, Czech Republic

Tel.+420 54949 8217, Fax. +420 541211 214, manakhov@ mail.muni.cz 


\begin{abstract}
:
Carboxyl coatings are extensively used for adhesion promotion, bio-immobilization and surface reactions thanks to their reactivity towards nucleophilic groups and high wettability. The deposition of relatively stable carboxyl-rich coatings using low-cost atmospheric pressure plasma processes is still challenging. This work is aimed at the investigation of the plasma copolymerization of maleic anhydride (MA) and $\mathrm{C}_{2} \mathrm{H}_{2}$ by atmospheric pressure dielectric barrier discharge. The quantification of the carboxyl groups is performed by X-ray photoelectron spectroscopy (XPS) C1s curve fitting and by derivatization with trifluoroethanol. The layer synthesized at optimized monomer flow rate and plasma power contains 5 at.\% of carboxyl groups (determined by derivatization combined with XPS) and exhibits the thickness loss below $5 \%$ after 128 hours in water. The influence of the MA: $\mathrm{C}_{2} \mathrm{H}_{2}$ ratio on the layer chemistry, morphology and stability is analyzed.
\end{abstract}

Keywords: Plasma co-polymerization, carboxyl films, maleic anhydride, XPS, derivatization 


\section{Introduction}

The deposition of functional organic thin films by plasma polymerization has become a promising technique able to prepare reactive surfaces for adhesion promotion [1-3], gas sensing [4,5], biosensing [6-8], immobilization of antibodies $[6,9,10]$, peptides $[11,12]$ and DNA [13,14], or cell adhesion enhancement [15-18]. The chemistry and morphology of plasma polymerized layers (PPLs) can be adjusted independently from the substrate nature by tuning the discharge parameter. For most applications, a sufficiently high surface concentration of functional groups as well as the layer stability in aqueous media is required [19-23]. Hegemann et al. showed that unstable plasma coatings release toxic oligomers poisoning the media and, therefore, cannot be used for biomedical applications [24,25]. Regardless of the nature of functional groups, carboxyls, amines, hydroxyls, epoxy and the like, a good stability of the PPLs requires a strong polymer cross-linking. In low pressure plasmas, it can be achieved by bombardment of energetic species formed in plasma [26,27]. Additionally, a higher-stronger cross-linking can be obtained by an increase of the input power or a decrease of the monomer flow, i. e. by an increased energy invested per monomer molecule leading to higher dissociation [23,28-31]. Unfortunately, it also leads to thehigher dissociation also means degradation of the functional groups due to the stronger monomer fragmentation $[19,32,33]$. Hence, the deposition of PPLs combining a high stability and a high density of functional groups is always challenging. It is even more difficult when the plasma polymerization is carried out at atmospheric pressure. The attractive energy-efficient and lowcost atmospheric pressure plasma polymerization generally leads to the deposition of PPLs that exhibit a lower water stability for a similar amount of functional groups as-compared to low pressure discharges [34-39]. The difficulties in obtaining a uniform gas distribution complicate achieving uniform coatings in terms of thickness and chemistry using atmospheric discharges. Moreover, the filamentary nature of dielectric barrier discharges (DBDs) causes 
local film non-uniformities or defects [40] and can lead to damage of temperature sensitive polymer substrates [41]. Therefore, it is advantageous to find a monomer which-whose admixture will lead to the ignition of DBD in a homogeneous mode. Recently, Eliáš et al. demonstrated that the so called atmospheric pressure glow discharge (APGD) can be ignited in the mixture of $\mathrm{Ar}$ and $\mathrm{C}_{2} \mathrm{H}_{2}$ [42].

Among the different reactive groups deposited by atmospheric pressure plasma polymerization, carboxyls $(\mathrm{COOH})$ are the most widely used for bioapplications thanks to their reactivity as well as high stability at air. One of the most widely used monomers for the atmospheric pressure plasma polymerization of carboxylСOОH-rich coatings is acrylic acid $[8,36,37,41,43]$ but other monomers like acetic acid [44] or maleic anhydride (MA) copolymerized with vinyltrimethoxysilane (VTMOS) [45-47] are used too. However, the investigation of carboxyl-rich PPLs deposited at atmospheric pressure has been quite limited. Carton et al. showed that carboxyl-rich PPLs deposited from He/acrylic acid plasma jet suffered large mass losses after immersion in water although the surface chemistry characterized by XPS was not significantly affected [36]. Morent et al. reported that the DBD plasma polymerization of acrylic acid led mostly to the deposition of soluble coatings [41]. According to Fourier transform infrared spectroscopy (FT-IR), the PPLs significantly dissolved after 5 minutes in water unless the maximum power was used.

Recently, Donegan et al. also confirmed the solubility of the PPLs deposited from acrylic acid by the PlasmaStream $\mathrm{He} / \mathrm{N}_{2}$ plasma jet [37]. However, the authors demonstrated that very thin $(<30 \mathrm{~nm})$ films containing 0.23 carboxyl groups per carbon atom and exhibiting a relatively good thickness and functional stability can be prepared by acrylic acid plasma polymerization in air using the PlasmaTreat jet. It should be noted that authors did not report the complete elemental composition of the surface or atomic density of carboxyl groups. IndeedOf course, the often observed incorporation of nitrogen atoms during the atmospheric 
plasma polymerization in air-can decrease the effective COOH density [48] can decrease the effective carboxyl density.

The important parameter for the bioapplications of carboxyl films is the concentration of carboxyl groups that is often estimated on the basis of XPS C1s curve fitting. However, it is impossible to distinguish the positions of the carbon peaks related to the carboxyl and ester groups and, therefore, the reported values include also "non-reactive" ester groups. Since Voronin et al. demonstrated that a high concentration of the carbon contribution at $289.2 \mathrm{eV}$ in plasma polymerized acrylic acid films does not always correspond to a high carboxyl group concentration, the chemical derivatization of carboxyl moieties is necessary [49]. As the derivatization of the carboxyl groups in the PPLs deposited at atmospheric pressure has not yet been reported, it is still debatable if a stable carboxyl-rich coating can be deposited by the atmospheric pressure plasma polymerization.

The copolymerization approach seems to be a promising method for tuning the carboxyl group density and the layer stability thanks to an additional control parameter, the ratio of two monomers. The first monomer is aimed at the incorporation of reactive carboxyl group (e.g. acrylic acid or MA) while the second ene-must provide the branched and well crosslinked network enhancing the layer stability (e.g. VTMOS, ethylene or acetylene). Hence, in theory, the cross-linking enhancement will not require an increased energy invested per monomer molecule and much higher structural retention of the first monomer can be expected. Nevertheless, the reported investigations of the carboxyl-rich plasma copolymers stability are very limited and often based only of theon IR spectroscopy measurements in attenuated total reflection (ATR) mode. Furthermore, the reported layers were immersed into water for short time periods only [46].

In this work, the MA and $\mathrm{C}_{2} \mathrm{H}_{2}$ (acetylene) co-polymerization using homogenous DBD is studied in order to optimize the carboxyl density and thickness stability of the PPLs. The 
influence of the MA: $\mathrm{C}_{2} \mathrm{H}_{2}$ flow rate ratio on the layer stability and carboxyl group density is analyzed. For the first time the chemical derivatization combined with XPS analysis (CDXPS) is employed to determine the carboxyl density in PPLs deposited at atmospheric pressure.

\section{Material and Methods}

\subsection{Plasma polymerization and diagnostics}

The deposition of thin films by DBD plasma co-polymerization of MA and $\mathrm{C}_{2} \mathrm{H}_{2}$ were-was carried out in a metallic cube chamber $(500 \times 500 \times 500 \mathrm{~mm})$. The discharge was ignited between planar metallic electrodes covered with $\mathrm{Al}_{2} \mathrm{O}_{3}$ ceramics, $1 \mathrm{~mm}$ in thickness. The top electrode, connected to the high voltage source, was divided into two rectangular pieces, each $20 \times 55 \mathrm{~mm}$. The bottom electrode, $150 \times 60 \mathrm{~mm}$, was grounded. The gases were supplied by a $1 \mathrm{~mm}$ slit placed between the high voltage electrodes. The gap between the top and bottom ceramics was $1.6 \mathrm{~mm}$. The polished crystalline silicon (c-Si) substrates were put on the bottom ceramics. The deposition uniformity was improved by moving the DBD top part with the gas mixture supply as schematically shown in Fig 1.

The MA pellets (Sigma-Aldrich, $99 \%$ ) were placed in a bubbling system and MA vapors were delivered into the discharge by Ar flow (Messer, $99.998 \%$ ). The flow rate of the second monomer, $\mathrm{C}_{2} \mathrm{H}_{2}$ (Messer, $99.6 \%$ ) was regulated directly by a flow controller in the range 2-3 sccm. The Ar flow rate through the bubbler, $Q_{\text {Ar-MA, was }} 0.25-1.5 \mathrm{slm}$. The flow rate of MA, $Q_{\mathrm{MA}}$, was calculated as $Q_{M A}=Q_{A r-M A} P_{M A} / P_{a t}$, where $P_{\mathrm{MA}}$ and $P_{\mathrm{at}}$ are vapour pressure of MA at $20{ }^{\circ} \mathrm{C}$, i.e. $22.3 \mathrm{~Pa}$, and atmospheric pressure, respectively. The total $\mathrm{Ar}$ flow rate $\left(Q_{\mathrm{Ar}}+Q_{\mathrm{Ar}-}\right.$ MA) was kept constant at $1.5 \mathrm{slm}$ thanks to the additional injection of Ar process gas passing MA bubbler. The deposition conditions are reported in Table 1. A hypothetical scheme of the 
$\mathrm{MA} / \mathrm{C}_{2} \mathrm{H}_{2}$ co-polymerization for the example of 1:3 MA: $\mathrm{C}_{2} \mathrm{H}_{2}$ ratio is drawn in Fig. 2. The scheme highlights a possible free radical co-polymerization and illustrates simply its expected mechanism.

Before the deposition the discharge chamber was pumped down to the pressure of $100 \mathrm{~Pa}$ and then filled up to $96 \mathrm{kPa}$ with a desired deposition gas mixture. The discharge was ignited by a sinusoidal high voltage from the generator with tunable frequency, $5.0-6.6 \mathrm{kHz}$. The power supplied by the generator was $8 \mathrm{~W}$.

The discharge voltage and current were monitored by the Agilent Technologies DSO1022A oscilloscope. Optical emission spectra (OES) of the discharge at various deposition conditions were recorded by the Avantes Sensline (AvaSpec-ULS2048LTEC) spectrometer in the wavelength range $330-1050 \mathrm{~nm}$. The signal at the wavelengths below 330 nm was limited by a thick glass window used as the view port. High resolution emission spectroscopy was performed with the spectrometer Horiba Jobin-Yvon FHR 1000 for an unambiguous identification of emission molecular bands.

\subsection{Characterization of Thin Films}

The film thicknesses were characterized by ellipsometry using a phase modulated Jobin Yvon UVISEL ellipsometer in the spectral region of 1.5-6.5 eV with-at the angle of incidence of $65^{\circ}$. Since the coatings exhibited very high roughness of upper boundaries and granular structure (see section Morphology of MA/ $\mathrm{C}_{2} \mathrm{H}_{2}$ PPLs) it was necessary to evaluate the film thickness in a manner useful for the film stability characterization. Therefore, we report the optical thicknesses (optical path lengths) [50] divided by the typical film refractive index $\approx$ 1.56 as the effective film thicknesses.

The transmittance in the spectral range from 370 to $7500 \mathrm{~cm}^{-1}$ was measured using Fourier Transform IR (FTIR) Bruker Vertex 80v spectrophotometer with a parallel beam 
transmittance accessory. The data were collected at pressure of $250 \mathrm{~Pa}$ with the resolution of 4 $\mathrm{cm}^{-1}$ and 500 scans. The transmittance of the films on Si substrate was divided by the transmittance of bare Si substrate in order to calculate a relative transmittance.

The topographies of upper surfaces of the coatings were analyzed using Bruker Dimension Icon atomic force microscope (AFM) in tapping mode. The rms of height differences $\sigma$ and autocorrelation length $T$ of roughness were determined by fitting the power spectrum density function of spatial frequencies [51].

The scanning electron microscopy (SEM) micrographs of the PPLs were obtained using Tescan LYRA3 XM microscope. The Au coating with a thickness of $15 \mathrm{~nm}$ was deposited by RF magnetron sputtering prior to the imaging in order to compensate for a charging. The electrons were accelerated by a $10 \mathrm{kV}$ high voltage and the working distance was fixed at 5 mm. Images of $1024 \times 1024$ pixels were acquired within 1 minute.

Prior to X-ray photoelectron spectroscopy (XPS) for a surface chemical characterization (6-9 $\mathrm{nm}$ depth), the PPLs were exposed to air for 24 hours in order to hydrolyze the anhydride groups to carboxyl moieties. The XPS was carried out using an Omicron X-ray source (DAR400, output power $270 \mathrm{~W}$ ) and an electron spectrometer (EA125) attached to a custom built ultra-high vacuum system. The quantitative composition was determined from detailed spectra taken at the pass energy of $25 \mathrm{eV}$ and the electron take-off angle $50^{\circ}$. The maximum lateral dimension of the analyzed area was $1.5 \mathrm{~mm}$. The quantification was carried out using XPS MultiQuant software [52]. The deconvolution of XPS C1s spectra to individual components was done in the CasaXPS software after subtraction of the Shirley background employing Gaussian-Lorentzian (G-L) peaks with the fixed G-L percentage $30 \%$ and the full width at a half maximum (FWHM) set to $1.85 \pm 0.05 \mathrm{eV}$. The high value of FWHM was caused by a non-monochromatized X-ray source used for the measurements and irregular structure of MA plasma polymers [46,47]. The binding energies (BE) of the corresponding 
carbon environments were taken from the work of Hody et al. [47]. The uncertainty of the peak area estimation for all components of the curve fitting were calculated by the Monte Carlo simulation routine embedded in the CasaXPS 2.3.16 software [53].

The concentration of carboxyl groups was determined according to the method proposed by Chilkoti et al. [54], i.e. by the reaction of trifluoroethanol with the PPLs (left 24 hours at air for hydrolysis of anhydride groups similarly as for XPS). For the reaction, the samples were placed on the glass slide inside the $100 \mathrm{~mL}$ flask. The $0.9 \mathrm{ml}$ of TFE (Sigma-Aldrich, 99\%.), $0.4 \mathrm{ml}$ of pyridine (Sigma Aldrich, $99.8 \%$ ) and $0.3 \mathrm{ml}$ of N,N'-Di-tertbutylcarbodiimide (Sigma Aldrich, 99\%) were subsequently dropped at the bottom of the flask with an interval of 15 minutes. The reaction was carried out for 3 hours in the closed flask at room temperature $\left(\sim 25^{\circ} \mathrm{C}\right)$. The atomic concentration of carboxyl groups, $[\mathrm{COOH}]$, was determined using Equation 1

$$
[\mathrm{COOH}]=\frac{[F]}{3[C]-2[F]}[\mathrm{C}] \quad \text { Equation } 1
$$

where $[\mathrm{C}]$ and $[\mathrm{F}]$ are atomic concentrations of carbon and fluorine, respectively, measured by XPS after the derivatization [55].

\section{Results}

\subsection{Electrical Characterization and OES}

The DBD voltage (U) and current (I) signal behavior was the same for all studied $\mathrm{Ar} / \mathrm{C}_{2} \mathrm{H}_{2} / \mathrm{MA}$ gas mixtures. For each half-period 6-7 relatively broad overlapping peaks in the current signal were recorded regardless of the polarity of the high-voltage electrode. A typical time resolved dependence of $U$ and I signals is depicted in Fig. S1 (see Supporting Information). Recently, it was shown that $\mathrm{DBD}$ in $\mathrm{Ar} / \mathrm{C}_{2} \mathrm{H}_{2}$ mixture can be ignited in the 
homogeneous mode, so called atmospheric pressure glow discharge (APGD) [42]. The appearance of several current peaks was attributed to the fact that the discharge did not burn in the whole discharge gap at the same time. However, the difference between the amount and sharpness of the current peaks in pure $\mathrm{Ar}$ or $\mathrm{Ar} / \mathrm{CH}_{4}$ and also the fast $\mathrm{CCD}$ camera imaging confirmed a non-filamentary nature of the discharge with admixed $\mathrm{C}_{2} \mathrm{H}_{2}$. The similarity of the I-U characteristics in Fig. 2 and already published results in $\mathrm{Ar} / \mathrm{C}_{2} \mathrm{H}_{2}$ suggests that the DBD in $\mathrm{Ar} / \mathrm{C}_{2} \mathrm{H}_{2} / \mathrm{MA}$ can be also running in the homogeneous mode. It can be advantageous for perspective coating of polymeric substrates, especially polymer nanofibers, by carboxylcontaining plasma polymers prepared in DBD.

Emission bands and atomic lines provided information about the dissociation of the monomers, although indirectly through the formation of excited species. The analysis of OES from different $\mathrm{MA} / \mathrm{C}_{2} \mathrm{H}_{2}$ mixtures revealed that the variation of the $\mathrm{MA}: \mathrm{C}_{2} \mathrm{H}_{2}$ ratio did not produce new peaks but the intensities of the existing peaks were changing. All the emission spectra contained numerous Ar lines. Other atomic lines such as $\mathrm{C}, \mathrm{H}$ or $\mathrm{O}$ were not present. Among molecular bands, the $\mathrm{CH}$ system at $431.3 \mathrm{~nm}$ and the $\mathrm{C}_{2}$ Swan system at $516.5 \mathrm{~nm}$ were identified. The presence of these two bands in the pure Ar discharge, albeit with small intensities, was caused by a contamination of the discharge from already coated electrodes.

The intensities are affected not only by the concentration of species in the ground state but also by excitation, dissociative excitation and quenching processes. In order to compensate for changes of the electron density, the intensities of $\mathrm{CH}$ and $\mathrm{C}_{2}$ bands were divided by the intensity of $\mathrm{Ar}$ line at $696.5 \mathrm{~nm}$ and plotted at function of $\mathrm{MA} / \mathrm{C}_{2} \mathrm{H}_{2}$ ratio in Fig.3. In the following paragraph, it served as the first approximation for the discussion of monomer dissociation because it is difficult to obtained densities of species by other methods.

The $\mathrm{CH}$ species can be considered as the last stage of the $\mathrm{MA}$ and $\mathrm{C}_{2} \mathrm{H}_{2}$ fragmentation in DBD because the atomic lines or CO bands, which could appear due to the fragmentation of 
MA, were not observed. The $\mathrm{C}_{2}$ Swan band generally represents an intermediate step of the dissociation or assembling of molecular species [56]. In this work case it could be an intermediate step of MA and $\mathrm{C}_{2} \mathrm{H}_{2}$ degradation. This hypothesis is was confirmed by the dependence of relative band intensities shown in Fig. 3. At a low MA: $\mathrm{C}_{2} \mathrm{H}_{2}$ ratio, the $\mathrm{C}_{2}$ band intensity is-was increasing much more slowly than the $\mathrm{CH}$ band, leading to the conclusion that most of MA monomer is-was dissociated to $\mathrm{CH}_{\mathrm{x}}$ fragments. As the MA: $\mathrm{C}_{2} \mathrm{H}_{2}$ ratio increases increased above 0.037 , the $\mathrm{CH}$ intensity startsstarted to decrease, whereas the $\mathrm{C}_{2}$ intensity increased steadily. Therefore, at high MA concentrations, the plasma power is not sufficient to fragment larger portion of monomer molecules to $\mathrm{CH}$ species and the intermediate $\mathrm{C}_{2}$ species are formed instead.

\subsection{Morphology of the $\mathrm{MA} / \mathrm{C}_{2} \mathrm{H}_{2}$ PPLs}

AFM revealed that all the films hadve a nanostructured surface composed of closely packed grains (Fig. 4). The surface roughness, $\sigma$, was 39-133 nm as reported in Table 1 . The ellipsometry data confirmed the high roughness of the films. Comparison of $\sigma$ and autocorrelation length $T$ for differently thick films deposited with the MA: $\mathrm{C}_{2} \mathrm{H}_{2}$ ratio of 0.110 (Figs. 4-c and 4-d) revealed that the surface topography was strongly influenced by the deposition time. It corresponds to the growth mode with high flux of depositing species that have relatively low surface mobility. The influenceeffect of the $\mathrm{MA}: \mathrm{C}_{2} \mathrm{H}_{2}$ ratio on the surface roughness is not clear. Its assessment would need to deposit a larger series of thefilms with different $\mathrm{MA}: \mathrm{C}_{2} \mathrm{H}_{2}$ ratios but the same thickness because the flux of depositing species varies with the monomer ratio. The high surface roughness of MA/C ${ }_{2} \mathrm{H}_{2}$ PPLs should enhance the cell adhesion or improve the biomolecules immobilization efficiency due to increased surface area. Therefore, these coatings can be advantageous for biomedical and biochemical applications supposed they contain sufficient amount of carboxyl moieties and exhibit a good 
stability in water. These two aspects, i.e. chemical composition and water stability of the layers, are discussed below.

\subsection{Chemical characterization of the $M A / C_{2} \mathrm{H}_{2}$ PPLs}

The high intensity of characteristic infrared absorption peaks of cyclic anhydride group, namely symmetric and asymmetric stretching of $\mathrm{C}=\mathrm{O}$ at 1787 and $1861 \mathrm{~cm}^{-1}$, respectively, and C-O-C deformations at 930, 1068 and $1231 \mathrm{~cm}^{-1}$ revealed a strong incorporation of anhydride groups into the MA/ $\mathrm{C}_{2} \mathrm{H}_{2}$ PPLs (Fig. 5) because these FT-IR measurements were performed just after the deposition (maximum 1 hour at air). The presence of a broad $\mathrm{C}-\mathrm{H}$ stretching peak around $2950 \mathrm{~cm}^{-1}$ indicated the polymerization of second monomer, acetylene. Additionally, the presence of broad $\mathrm{OH}$ peak around $3360 \mathrm{~cm}^{-1}$ and $\mathrm{C}=\mathrm{O}$ stretching of carboxyl group at $\sim 1730 \mathrm{~cm}^{-1}$ confirmed the partial fragmentation of MA and its hydrolysis during or immediately after the deposition. The layer deposited with the $\mathrm{MA}: \mathrm{C}_{2} \mathrm{H}_{2}$ ratio of 0.020 exhibited higher intensity of carboxyl peak compared to the anhydride peak, whereas the carboxyl peak iswas almost negligible compared to the anhydride band in the PPL deposited with the MA: $\mathrm{C}_{2} \mathrm{H}_{2}$ ratio of 0.110 . Taking into account relative intensity of anhydride over carboxyl peak, it became clear that the fragmentation of MA monomer decreased with the MA: $\mathrm{C}_{2} \mathrm{H}_{2}$ ratio. However, the presence of $\mathrm{sp}^{2} \mathrm{C}-\mathrm{H}$ stretching at $3117 \mathrm{~cm}^{-1}$ indicated that for the highest $\mathrm{MA}: \mathrm{C}_{2} \mathrm{H}_{2}$ ratio some MA molecules were not polymerized via the free radical mechanism for the highest $\mathrm{MA}: \mathrm{C}_{2} \mathrm{H}_{2}$ ratio. Therefore, at these conditions the unpolymerized monomer molecules or oligomers were entrapped in the coating. In order to properly compare the surface chemistry of these four PPLs, the XPS analysis combined with chemical derivatization was essential.

According to the XPS analyses, all the as-deposited PPLs were composed from carbon and oxygen only (hydrogen cannot be detected by XPS). The O/C ratio increased with the MA: $\mathrm{C}_{2} \mathrm{H}_{2}$ ratio as an exponential decay function that leveled out above $\mathrm{MA}: \mathrm{C}_{2} \mathrm{H}_{2}=0.055$ 
(Fig. 6). It indicates that the concentration of the "oxidized" carbon including carboxyl groups was increasing with the MA concentration in the gas mixture. However, the XPS C1s curve fitting was necessary in order to analyze $\underline{\mathbf{C}}(\mathrm{O}) \mathrm{O}$ environment.

The XPS C1s curve fitting of all layers was performed with a sum of five components (Fig. 7), namely hydrocarbons $\left(\underline{\mathbf{C H}}_{\mathrm{x}}, \mathrm{BE} 285.0 \mathrm{eV}\right)$, carbon singly bonded to oxygen $(\underline{\mathbf{C}}-\mathrm{O}$, $\mathrm{BE} \sim 286.5 \mathrm{eV})$, carbon doubly bonded to oxygen $(\underline{\mathbf{C}}=\mathrm{O}, \mathrm{BE} \sim 287.9 \mathrm{eV})$, carbon of ester or carboxyl group $(\underline{\mathbf{C}}(\mathrm{O}) \mathrm{O}, \mathrm{BE} \sim 289.1 \mathrm{eV})$ and unsaturated carbon $(\underline{\mathbf{C}}=\underline{\mathbf{C}}, \mathrm{BE} \sim 283.9 \mathrm{eV})$. The first four components were identified also by FTIR and they are typically presented in the MA plasma polymers $[46,47,57]$. The $\mathrm{C}=\mathrm{C}$ bonds was visible in the FT-IR of the PPL deposited with the highest MA: $\mathrm{C}_{2} \mathrm{H}_{2}$, thusevidencing incorporated unpolymerized MA or oligomers. The unfinished polymerization of the MA at very high MA flow rate was confirmed by XPS (Fig. 7-a) but it should be noted that the presence of the $\mathrm{C}=\mathrm{C}$ component observed by XPS for all the MA: $\mathrm{C}_{2} \mathrm{H}_{2}$ ratios can be also attributed to the $\pi$-bond related to the incomplete polymerization of $\mathrm{C}_{2} \mathrm{H}_{2}$ acetylene.

The $\underline{\mathbf{C H}}_{\mathrm{x}}$ and $\underline{\mathbf{C}}(\mathrm{O}) \mathrm{O}$ contributions of the XPS C1s peak are plotted in Fig. 6 for a better understanding of the monomer fragmentation and the incorporation of carboxyl groups, whereas the percentages of all carbon environments can be found in Table S1 (see Supporting Information). The hydrocarbon environment was decreasing with the $\mathrm{MA}: \mathrm{C}_{2} \mathrm{H}_{2}$ ratio. $\mathrm{A}$ higher flow rate of MA led to an increase of the $\underline{\mathbf{C}}(\mathrm{O}) \mathrm{O}$ component, i. e. carboxyl or ester groups, up to 13.1 at.\%. Hence, the obtained atomic percentage is comparable with the previously reported compositions of MA plasma polymers deposited at atmospheric pressure $[46,47]$ but slightly lower than the 17.3 at.\% of $\underline{\mathbf{C}}(\mathrm{O}) \mathrm{O}$ obtained by Mishra and McArthur in low pressure plasma polymerization of MA [58].

Since cell adhesion and immobilization of any kind of biomolecules can be realized by the reaction with carboxyl groups but not with the ester bonds, it is very important to determine 
the true carboxyl concentration, $[\mathrm{COOH}]$. The chemical derivatization of carboxyl groups followed by XPS analysis according to Equation 1 revealed that [COOH] was smaller than $\underline{\mathbf{C}}(\mathrm{O}) \mathrm{O}$ concentration derived from the $\mathrm{C} 1$ s curve fitting. The highest carboxyl concentration of 8 at.\% was found for the PPLs obtained with the MA: $\mathrm{C}_{2} \mathrm{H}_{2}$ ratio of 0.110 . Hence, not more than $60 \%$ of $\underline{\mathbf{C}}(\mathrm{O}) \mathrm{O}$ represents the carboxyl environment, the rest being the ester groups. Anyway, all the presented PPLs exhibited $[\mathrm{COOH}]$ in the range from 4 to 8 at. $\%$, i.e. at values comparable to the low pressure acrylic acid plasma polymerization results [49]. These values can be considered sufficient for bioapplications.

\subsection{Water Stability of $\mathrm{MA} / \mathrm{C}_{2} \mathrm{H}_{2}$ PPLs.}

The analysis of the thickness, morphology and chemical changes after immersion in water is very important for the understanding of the stability of PPLs and their suitability for cell cultivation or biosensing application. SEM imaging revealed that regardless the plasma conditions, the MA/ $\mathrm{C}_{2} \mathrm{H}_{2}$ PPLs after immersion in water for 24 hours did not induce a delamination of layers and micro/macro-cracks has been observed (see Fig. S2 in Supporting Information).

As shown in Fig. 8, the immersion of MA/ $\mathrm{C}_{2} \mathrm{H}_{2}$ PPLs led to different changes of the film thickness, depending on plasma condition. The film deposited at the lowest $\mathrm{MA}: \mathrm{C}_{2} \mathrm{H}_{2}$ ratio exhibited an increase of the effective thickness by $20 \%$, probably due to a film swelling observed before for the low pressure plasma polymerized MA[59-60]. However, the high magnification SEM micrographs did not reveal any morphological changes in this layer after immersion, as shown in Fig.9-a The PPL deposited at MA: $\mathrm{C}_{2} \mathrm{H}_{2}=0.037$ exhibited the best results for the thickness change after immersion, as it was within the estimated uncertainties. Nevertheless, the SEM micrographs revealed some changes in the structure of layer After immersion. As shown in Fig. 9-b, the nanostructures formed dense agglomerates after immedrsion and it was accompanied with the formation of sub-micrometer pores. A further 
increase of the $\mathrm{MA}: \mathrm{C}_{2} \mathrm{H}_{2}$ ratio led to a significant thickness loss already after one hour of immersion in water. The film deposited at the ratio of 0.055 exhibited the thickness loss around $20 \%$ after one hour in water and it was not significantly changing for longer immersion. The PPL synthesized at the highest $\mathrm{MA}: \mathrm{C}_{2} \mathrm{H}_{2}$ ratio lost $70 \%$ of its thickness after one hour and the layer continued to dissolve even after 24 and 128 hours of immersion. SEM imaging also revealed significant changes in the morphology of this layer after immersion. As shown in Fig. 9-c, the nanostructures were agglomerating and they formed microstructures with a sub-micrometer porosity. Such high dissolution and instability was caused by the low polymer cross-linking and the presence of unpolymerized MA molecules revealed by FT-IR and XPS. Additionally, the high density of hydrophilic groups including carboxyl could strongly increase solubility of this film in water.

Regarding the water stability of carboxyl groups, the TFE derivatization of the PPLs after 128 hours of immersion revealed a significant decrease of $[\mathrm{COOH}]$ (Fig. 8). The highest $[\mathrm{COOH}]$ after immersion, 2.4 at.\%, was found at the surface of PPL deposited with MA: $\mathrm{C}_{2} \mathrm{H}_{2}$ $=0.037$.

The intensity of the infrared carbonyl peak (in the range from 1840 to $1650 \mathrm{~cm}^{-1}$ ) of $\mathrm{MA} / \mathrm{C}_{2} \mathrm{H}_{2}$ PPLs before and after water immersion was integrated and normalized to the layer thickness for a confirmation of the XPS results. The measurements before water immersion (values for the immersion time of $0 \mathrm{~h}$ ) were performed after aging for 24 hour in air in order to complete the hydrolysis of anhydrides present in the films after the deposition. This procedure, adopted also for the chemical derivatization studies, allowed comparing the water stability of carboxyl groups without the influence of their addition due to hydrolysis of anhydridesin water. As shown in Fig. 10, the intensity of carbonyl peak for PPLs deposited with the MA: $\mathrm{C}_{2} \mathrm{H}_{2}$ ratio from between 0.020 and 0.055 iswas decreasing with the immersion time, while the layer deposited with ratio of 0.110 exhibited an increase of the normalized 
integrated intensity of $\mathrm{C}=\mathrm{O}$ peak. The large disagreement between the FTIR and XPS results can be explained by an extremely high solubility of this film. The normalization of the intensities in the FTIR spectra can be reasonable if the thickness fluctuates in a small range, e.g. within 10-20\% of the nominal value, as it was observed for the PPLs deposited with smaller MA: $\mathrm{C}_{2} \mathrm{H}_{2}$ ratios. However, when the thickness is changing by $70-80 \%$, the normalization cannot be easily performed due to non-linear dependence of the IR peaks intensity on the layer thickness. Hence, the results shown for the MA: $\mathrm{C}_{2} \mathrm{H}_{2}$ ratio of 0.110 cannot be relied upon. should not be taken int a the FTIR data supports the XPS result that carboxyl groups degraded in water.

The results on the water stability of carboxyl films deposited by the $\mathrm{MA} / \mathrm{C}_{2} \mathrm{H}_{2}$ copolymerization in atmospheric pressure DBD differ significantly from the work of Carton et al. [36] reporting the good chemical stability of the carboxyl films prepared by acrylic acid polymerization in atmospheric pressure plasma jet in spite of the 50-90 \% of the-weight loss after 24 hours immersion in water. In this work, the smallest decrease of the $[\mathrm{COOH}]$ was $50 \%$ for the layer exhibiting a negligible thickness change, i.e. very low solubility in water. Hence, the concentration of carboxyl groups in MA/ $\mathrm{C}_{2} \mathrm{H}_{2}$ PPLs decreased more rapidly compared to the films prepared from acrylic acid and it mightthis may be related to a higher reactivity of MA compared to acrylic acid.

Comparing the hereby reported results to the work of Morent et al. [41] on the atmospheric pressure plasma polymerization of acrylic acid it can be concluded that $\mathrm{MA} / \mathrm{C}_{2} \mathrm{H}_{2}$ plasma copolymerization leads to a better stability, whereas the $\underline{\mathbf{C}}(\mathrm{O}) \mathrm{O}$ environment is comparable in both cases. Nevertheless, the mentioned authors used only ATR-FTIR for the investigation of the layer stability, while here the stability was thoroughly studied by the thickness measurement, FT-IR and CD-XPS. 


\section{Conclusion}

The chemical composition and water stability of carboxyl PPLs prepared by atmospheric pressure plasma co-polymerization of MA and $\mathrm{C}_{2} \mathrm{H}_{2}$ were investigated by thickness measurement, FT-IR, XPS and CD-XPS. The high deposition rates (up to $94 \mathrm{~nm} / \mathrm{min}$ ) and surface roughness (over $100 \mathrm{~nm}$ ) of the layers was were caused by the continuous wave excitation and high power of the DBD. The well-known CD-XPS method revealed that the surface concentration of carboxyl groups was significantly lower than the $\underline{\mathbf{C}}(\mathrm{O}) \mathrm{O}$ component derived from the XPS C1s curve fitting and, therefore, a large portion of ester groups iswas present together with the carboxyl moieties.

The advantage of co-polymerization was clearly shown because the deposition of stable carboxyl-rich PPLs was achieved at an appropriate choice of the ratio of monomer flow rates. Insufficient concentration of MA led to a layer swelling accompanied with the low concentration of carboxyl groups, while the excess of MA led to the deposition of soluble films. At the optimized MA: $\mathrm{C}_{2} \mathrm{H}_{2}$ ratio of 0.037 the negligible thickness change accompanied with the 10.5 at.\% of $\underline{\mathbf{C}}(\mathrm{O}) \mathrm{O}$ (derived from XPS C1s curve fitting) and more than 5 at. $\%$ carboxyl groups (estimated by the TFE derivatization) was observed for this coating. Nevertheless, the concentration of the carboxyl groups decreased by $50 \%$, to 2.5 at. $\%$, after 128 hour in water. The high thickness stability accompanied with the sufficiently high carboxyl groups density estimated by the TFE derivatization has never been reported before for the carboxyl plasma polymers deposited at atmospheric pressure. The sufficient long-term layer stability in water combined with 5 at.\% of carboxyl groups and high surface roughness make this type of layers highly attractive for biological applications.

\section{Acknowledgements}

This work was supported by the COST CZ project LD14036 financed by the Ministry of Education of the Czech Republic and BioFibPlas project No. 3SGA5652 financed from the 
SoMoPro II Programme that has acquired a financial grant from the People Programme (Marie Curie Action) of the Seventh Framework Programme of EU according to the REA Grant Agreement No. 291782 and was further co-financed by the South-Moravian Region. The research was also supported by the project "CEITEC — Central European Institute of Technology" (CZ.1.05/1.1.00/02.0068) from the European Regional Development Fund. The authors also gratefully acknowledge the SCOPES grant IZ73Z0_152661 funded by Swiss National Science Foundation. This publication reflects only the authors' views and the Union is not liable for any use that may be made of the information contained therein.

\section{References}

[1] M. Moreno-Couranjou, A. Manakhov, N.D. Boscher, J.-J. Pireaux, P. Choquet, A novel dry chemical path way for diene and dienophile surface functionalization toward thermally responsive metal-polymer adhesion., ACS Appl. Mater. Interfaces. 5 (2013) $8446-56$.

[2] R.A. D’Sa, G. Burke, B.J. Meenan, Protein adhesion and cell response on atmospheric pressure dielectric barrier discharge-modified polymer surfaces., Acta Biomater. 6 (2010) 2609-20.

[3] Y.P. Li, Z.C. Zhang, W. Shi, M.K. Lei, Adhesion enhancement of polyethylene modified by capacitively coupled radio frequency plasma polymerization of ethanol, Surf. Coatings Technol. 259 (2014) 77-82.

[4] N.D. Boscher, D. Duday, P. Heier, K. Heinze, F. Hilt, P. Choquet, Plasma polymer membranes for immobilising metalloporphyrins, Plasma Process. Polym. 10 (2013) $336-344$.

[5] N.D. Boscher, D. Duday, P. Heier, K. Heinze, F. Hilt, P. Choquet, Atmospheric pressure plasma polymerisation of metalloporphyrins containing mesoporous membranes for gas sensing applications, Surf. Coatings Technol. 234 (2013) 48-52.

[6] A. Manakhov, P. Skládal, D. Nečas, J. Čechal, J. Polčák, M. Eliáš, L. Zajíčková , Cyclopropylamine plasma polymers deposited onto quartz crystal microbalance for biosensing application, Phys. Status Solidi. A 211 (2014) 2801-2808.

[7] H. Muguruma, Plasma-polymerized films for biosensors, Trends Anal. Chem. 18 (1999) 62-68. 
[8] G.B. Rusu, M. Asandulesa, I. Topala, V. Pohoata, N. Dumitrascu, M. Barboiu, Atmospheric pressure plasma polymers for tuned QCM detection of protein adhesion., Biosens. Bioelectron. 53 (2014) 154-9.

[9] A. Artemenko, H. Kozak, H. Biederman, A. Choukourov, Amination of NCD Films for Possible Application in Biosensing, Plasma Process. Polym. 12 (2015) 336-346.

[10] K. Nakanishi, H. Muguruma, I. Karube, A novel method of immobilizing antibodies on a quartz crystal microbalance using plasma-polymerized films for immunosensors., Anal. Chem. 68 (1996) 1695-700.

[11] B.R. Coad, M. Jasieniak, S.S. Griesser, H.J. Griesser, Controlled covalent surface immobilisation of proteins and peptides using plasma methods, Surf. Coatings Technol. 233 (2013) 169-177.

[12] D. Duday, C. Vreuls, M. Moreno, G. Frache, N. D. Boscher, G. Zocchi, C. Archambeau, C. Van De Weerdt, J. Martial, P. Choquet, Atmospheric pressure plasma modified surfaces for immobilization of antimicrobial nisin peptides, Surf. Coatings Technol. 218 (2013).

[13] Z. Zhang, Q. Chen, W. Knoll, R. Foerch, R. Holcomb, D. Roitman, Plasma Polymer Film Structure and DNA Probe Immobilization, Macromolecules. 36 (2003) 76897694.

[14] S. Ricciardi, R. Castagna, S. M. Severino, I. Ferrante, F. Frascella, E. Celasco, P. Mandracci, I. Vallini, G. Mantero, C. F. Pirri, P. Rivolo, Surface functionalization by poly-acrylic acid plasma-polymerized films for microarray DNA diagnostics, Surf. Coatings Technol. 207 (2012) 389-399.

[15] P.-L. Girard-Lauriault, F. Truica-Marasescu, A. Petit, H. T. Wang, P. Desjardins, J. Antoniou, F. Mwale, M. R. Wertheimer, Adhesion of human U937 monocytes to nitrogen-rich organic thin films: novel insights into the mechanism of cellular adhesion., Macromol. Biosci. 9 (2009) 911-21.

[16] H.-U. Lee, Y.-S. Jeong, S.-Y. Jeong, S.-Y. Park, J.-S. Bae, H.-G. Kim, C.-R. Cho, Role of reactive gas in atmospheric plasma for cell attachment and proliferation on biocompatible poly ع-caprolactone film, Appl. Surf. Sci. 254 (2008) 5700-5705.

[17] D. Zeniieh, A. Bajwa, L. Ledernez, G. Urban, Effect of plasma treatments and plasmapolymerized films on the adhesion of parylene-C to substrates, Plasma Process. Polym. 10 (2013) 1081-1089.

[18] A.G. Guex, D. Hegemann, M.N. Giraud, H.T. Tevaearai, A.M. Popa, R.M. Rossi, G. Fortunato, Colloids and Surfaces B : Biointerfaces Covalent immobilisation of VEGF on plasma-coated electrospun scaffolds for tissue engineering applications, Colloids Surfaces B Biointerfaces. 123 (2014) 724-733.

[19] K.S. Siow, L. Britcher, S. Kumar, H.J. Griesser, Plasma Methods for the Generation of Chemically Reactive Surfaces for Biomolecule Immobilization and Cell Colonization A Review, Plasma Process. Polym. 3 (2006) 392-418. 
[20] A. Manakhov, L. Zajíčková, M. Eliáš, J. Čechal, J. Polčák, J. Hnilica, Š. Bittnerová, D. Nečas, Optimization of Cyclopropylamine Plasma Polymerization toward Enhanced Layer Stability in Contact with Water, Plasma Process. Polym. 11 (2014) 532-544.

[21] A. Manakhov, D. Nečas, J. Čechal, D. Pavliňák, M. Eliáš, L. Zajíčková, Deposition of stable amine coating onto polycaprolactone nanofibers by low pressure

cyclopropylamine plasma polymerization, Thin Solid Films. 581 (2015) 7-13.

[22] E. Lecoq, D. Duday, S. Bulou, G. Frache, F. Hilt, R. Maurau, P. Choquet, Plasma polymerization of APTES to elaborate nitrogen containing organosilicon thin films: Influence of process parameters and discussion about the growing mechanisms, Plasma Process. Polym. 10 (2013) 250-261.

[23] J.-C. Ruiz, A. St-Georges-Robillard, C. Thérésy, S. Lerouge, M.R. Wertheimer, Fabrication and Characterisation of Amine-Rich Organic Thin Films: Focus on Stability, Plasma Process. Polym. 7 (2010) 737-753.

[24] M. Drabik, J. Kousal, C. Celma, P. Rupper, H. Biederman, D. Hegemann, Influence of Deposition Conditions on Structure and Aging of C:H:O Plasma Polymer Films Prepared from Acetone/CO2 Mixtures, Plasma Process. Polym. 11 (2014) 496-508.

[25] D. Hegemann, B. Hanselmann, S. Guimond, G. Fortunato, M.-N. Giraud, A.G. Guex, Considering the degradation effects of amino-functional plasma polymer coatings for biomedical application, Surf. Coatings Technol. 255 (2014) 90-95.

[26] L. Denis, D. Thiry, D. Cossement, P. Gerbaux, F. Brusciotti, I. Van De Keere, V. Goossens, H. Terryn, M. Hecq, R. Snyders, Towards the understanding of plasma polymer film behaviour in ethanol: A multi-technique investigation, Prog. Org. Coatings. 70 (2011) 134-141.

[27] S. Ligot, E. Bousser, D. Cossement, J. Klemberg-Sapieha, P. Viville, P. Dubois, R. Snyders, Correlation Between Mechanical Properties and Cross-Linking Degree of Ethyl Lactate Plasma Polymer Films, Plasma Process. Polym. 12 (2015) 508-518

[28] L. Denis, P. Marsal, Y. Olivier, T. Godfroid, R. Lazzaroni, M. Hecq, J. Cornil, R. Snyders, Deposition of Functional Organic Thin Films by Pulsed Plasma Polymerization: A Joint Theoretical and Experimental Study, Plasma Process. Polym. 7 (2009) 172-181.

[29] A. Abbas, C. Vivien, B. Bocquet, D. Guillochon, P. Supiot, Preparation and MultiCharacterization of Plasma Polymerized Allylamine Films, Plasma Process. Polym. 6 (2009) 593-604.

[30] S. Guimond, B. Hanselmann, M. Hossain, V. Salimova, D. Hegemann, Deposition of Plasma Polymer Films from Acetylene and Water Vapor, 12(2015) 328-335.

[31] E. Kedroňová, L. Zajíčková, D. Hegemann, M. Klíma, M. Michlíček, A. Manakhov, Plasma Enhanced CVD of Organosilicon Thin Films on Electrospun Polymer Nanofibers, Plasma Process. Polym. (2015) doi:10.1002/ppap.201400235. 
[32] A. Contreras-García, M.R. Wertheimer, Low-Pressure Plasma Polymerization of Acetylene-Ammonia Mixtures for Biomedical Applications, Plasma Chem. Plasma Process. 33 (2012) 147-163.

[33] J. Ruiz, M.R. Wertheimer, Fabrication, Characterization , and Comparison of OxygenRich Organic Films Deposited by Plasma- and Vacuum-Ultraviolet ( VUV ), Plasma Process. Polym. 12(2015) 225-236.

[34] J. Friedrich, R. Mix, R.-D. Schulze, a. Rau, Ultra-Thin Polymer Layer Deposition by Aerosol-Dielectric Barrier Discharge (DBD) and Electrospray Ionization (ESI) at Atmospheric Pressure, J. Adhes. Sci. Technol. 24 (2010) 1329-1350.

[35] A. Batan, B. Nisol, A. Kakaroglou, I. De Graeve, G. Van Assche, B. Van Mele, H. Terryn, F. Reniers, The impact of double bonds in the APPECVD of acrylate-like precursors, Plasma Process. Polym. 10 (2013) 857-863.

[36] O. Carton, D. Ben Salem, S. Bhatt, J. Pulpytel, F. Arefi-Khonsari, Plasma polymerization of acrylic acid by atmospheric pressure nitrogen plasma jet for biomedical applications, Plasma Process. Polym. 9 (2012) 984-993. doi:10.1002/ppap.201200044.

[37] M. Donegan, D.P. Dowling, Protein adhesion on water stable atmospheric plasma deposited acrylic acid coatings, Surf. Coatings Technol. 234 (2013) 53-59.

[38] R. Mauchauffé, M. Moreno-Couranjou, N.D. Boscher, C. Van De Weerdt, A.-S. Duwez, P. Choquet, Robust bio-inspired antibacterial surfaces based on the covalent binding of peptides on functional atmospheric plasma thin films, J. Mater. Chem. B. 2 (2014) 5168. doi:10.1039/C4TB00503A.

[39] M. Bashir, J.M. Rees, W.B. Zimmerman, Plasma polymerization in a microcapillary using an atmospheric pressure dielectric barrier discharge, Surf. Coatings Technol. 234 (2013) 82-91.

[40] D. Trunec, Z. Navrátil, P. Stahel, L. Zají ková, V. Bur íková, J. Cech, Deposition of thin organosilicon polymer films in atmospheric pressure glow discharge, J. Phys. D. Appl. Phys. 37 (2004) 2112-2120.

[41] R. Morent, N. De Geyter, M. Trentesaux, L. Gengembre, P. Dubruel, C. Leys, E. Payen, Stability study of polyacrylic acid films plasma-polymerized on polypropylene substrates at medium pressure, Appl. Surf. Sci. 257 (2010) 372-380.

[42] M. Eliáš, P. Kloc, O. Jašek, V. Mazánková, D. Trunec, R. Hrdý, L. Zajíčková, Atmospheric pressure barrier discharge at high temperature: Diagnostics and carbon nanotubes deposition, J. Appl. Phys. 117 (2015) 103301.

[43] A. J. Beck, R.D. Short, A. Matthews, Deposition of functional coatings from acrylic acid and octamethylcyclotetrasiloxane onto steel using an atmospheric pressure dielectric barrier discharge, Surf. Coatings Technol. 203 (2008) 822-825. 
[44] M.F. Dubreuil, E.M. Bongaers, Use of atmospheric pressure plasma technology for durable hydrophilicity enhancement of polymeric substrates, Surf. Coatings Technol. 202 (2008) 5036-5042.

[45] A. Manakhov, M. Moreno-Couranjou, P. Choquet, N.D. Boscher, J.-J.J. Pireaux, Diene functionalisation of atmospheric plasma copolymer thin films, Surf. Coatings Technol. 205 (2011) S466-S469.

[46] A. Manakhov, M. Moreno-Couranjou, N.D. Boscher, V. Roge, P. Choquet, J.J. Pireaux, Atmospheric pressure pulsed plasma copolymerisation of maleic anhydride and vinyltrimethoxysilane: Influence of electrical parameters on chemistry, morphology and deposition rate of the coatings, Plasma Process. Polym. 9 (2012) 435445 .

[47] H. Hody, P. Choquet, M. Moreno-Couranjou, R. Maurau, J.-J. Pireaux, Optimization of Carboxyl Surface Functionalization by MA-VTMS Copolymerization Using Atmospheric Pressure Plasma DBD: Influence of the Carrier Gas, Plasma Process. Polym. 7 (2010) 403-410.

[48] R. Maurau, N.D. Boscher, J. Guillot, P. Choquet, Nitrogen Introduction in pp-HMDSO Thin Films Deposited by Atmospheric Pressure Dielectric Barrier Discharge: An XPS Study, Plasma Process. Polym. 9 (2012) 316-323.

[49] S. Voronin, M. Zelzer, C. Fotea, M.R. Alexander, J.W. Bradley, Pulsed and continuous wave acrylic acid radio frequency plasma deposits: plasma and surface chemistry., J. Phys. Chem. B. 111 (2007) 3419-29.

[50] Z. Knittl, Optics of Thin Films, Wileys\&Sons, London, p.104, 1976.

[51] D. Franta, I. Ohlidal, P. Klapetek, Analysis of slightly rough thin films by optical methods and AFM, Mikrochim. Acta. 132 (2000) 443-447.

[52] M. Mohai, XPS MultiQuant: multimodel XPS quantification software, Surf. Interface Anal. 36 (2004) 828-832.

[53] CasaXPS Manual 2.3.16, (2010) 18. http://www.casaxps.com/help_manual/manual_updates/manual2316/AtomicConcentrat ionUncertainties.pdf (accessed September 16, 2015)

[54] A. Chilkoti, B. Ratner, D. Briggs, Plasma-deposited polymeric films prepared from carbonyl-containing volatile precursors: XPS chemical derivatization and static SIMS surface characterization, Chem. Mater. (1991) 51-61.

[55] A. Fahmy, R. Mix, A. Schönhals, J. Friedrich, Structure of plasma-deposited copolymer films prepared from acrylic acid and styrene: Part i dependence on the duty cycle, Plasma Process. Polym. 9 (2012) 273-284.

[56] P. Heyse, R. Dams, S. Paulussen, K. Houthoofd, K. Janssen, P. Jacobs, B. F. Sels., Dielectric barrier discharge at atmospheric pressure as a tool to deposit versatile organic coatings at moderate power input, Plasma Process. Polym. 4 (2007) 145-157. 
[57] M. Ryan, A. Hynes, J. Badyal, Pulsed plasma polymerization of maleic anhydride, Chem. Mater. (1996) 37-42.

[58] G. Mishra, S.L. McArthur, Plasma polymerization of maleic anhydride: just what are the right deposition conditions?, Langmuir 26 (2010) 9645-58.

[59] J. Drews, H. Launay, C. M. Hansen, K. West, S. Hvilsted, P. Kingshott, K. Almdal, Hydrolysis and stability of thin pulsed plasma polymerised maleic anhydride coatings, Appl. Surf. Sci. 254 (2008) 4720-4725. doi:10.1016/j.apsusc.2008.01.085.

[60] S. Schiller, J. Hu, A. Jenkins, Chemical structure and properties of plasma-polymerized maleic anhydride films, Chem. Mater. 14 (2002) 235-242. 


\section{Figure Captions}

Fig. 1 Schema of DBD setup.

Fig. 2 The proposed scheme of the $\mathrm{MA} / \mathrm{C}_{2} \mathrm{H}_{2}$ copolymerization.

Fig. 3 The intensity of $\mathrm{CH}$ and $\mathrm{C}_{2}$ bands divided by the intensity of $\mathrm{Ar}$ line at $696.5 \mathrm{~nm}$ as a function of MA: $\mathrm{C}_{2} \mathrm{H}_{2}$ ratio in $\mathrm{Ar} / \mathrm{C}_{2} \mathrm{H}_{2} / \mathrm{MA}$ DBDs. The band intensities in pure Ar DBD (open symbols) were recorded for comparison too.

Fig. 4 Surface topography of MA/C ${ }_{2} \mathrm{H}_{2}$ PPLs measured by AFM. The micrographs (a) - (c) demonstrate surface topography of the films with thickness around $500 \mathrm{~nm}$ for different MA: $\mathrm{C}_{2} \mathrm{H}_{2}$ ratios, (a) 0.020 , (b) 0.037 and (c) 0.110 . Comparison of (c) and (d) reveals the difference between topography of differently thick films, (c) $417 \mathrm{~nm}$ and (d) $938 \mathrm{~nm}$ for the same MA: $\mathrm{C}_{2} \mathrm{H}_{2}=0.110$. All images have the $x: y: z$ scale of $1: 1: 1$.

Fig. 5 FTIR spectra (absorbance normalized to the effective film thickness) of the asdeposited MA/ $\mathrm{C}_{2} \mathrm{H}_{2}$ PPLs prepared with different MA: $\mathrm{C}_{2} \mathrm{H}_{2}$ flow rate ratios. The absorbance curves are shifted by a constant value.

Fig. 6 The $\mathrm{O} / \mathrm{C}$ ratio, $\mathrm{CH}_{\mathrm{x}}$ and $\mathrm{C}(\mathrm{O}) \mathrm{O}$ concentrations as functions of the $\mathrm{MA}: \mathrm{C}_{2} \mathrm{H}_{2}$ ratio.

Fig. 7 XPS C1s curve fitting of $\mathrm{MA} / \mathrm{C}_{2} \mathrm{H}_{2}$ PPLs prepared with (a) 0.11 and (b)0.02 monomer ratio.

Fig. 8 Concentration of carboxyl groups $[\mathrm{COOH}]$ estimated by CD-XPS and the thickness loss of MA/ $\mathrm{C}_{2} \mathrm{H}_{2}$ PPLs as a function of the monomer flow rate ratio MA: $\mathrm{C}_{2} \mathrm{H}_{2}$.

Fig. 9 High magnification SEM micrographs of the MA/C $\mathrm{C}_{2} \mathrm{H}_{2}$ PPLs before (on left) and after (on right) immersion in water for 24 hours a) $\mathrm{MA} / \mathrm{C}_{2} \mathrm{H}_{2}=0.02$, b) $\mathrm{MA} / \mathrm{C}_{2} \mathrm{H}_{2}=0.037$, c) $\mathrm{MA} / \mathrm{C}_{2} \mathrm{H}_{2}=0.11$ 
Fig. 10 The behavior of normalized integrated intensity of carbonyl peaks depending on immersion time of $\mathrm{MA} / \mathrm{C}_{2} \mathrm{H}_{2}$ PPLs prepared with different monomer ratios. 


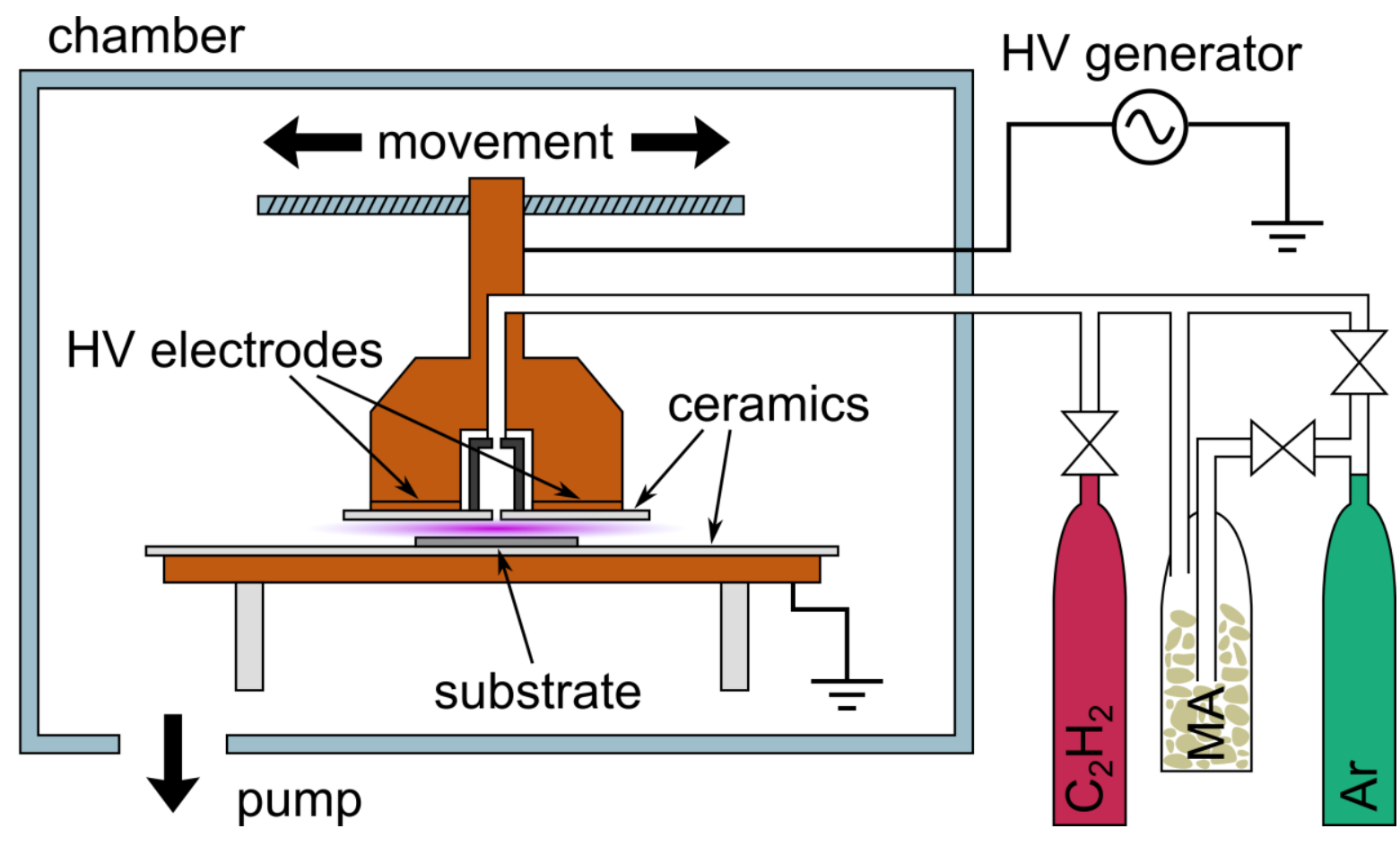


<smiles>O=C1C=CC(=[OH+])O1</smiles>

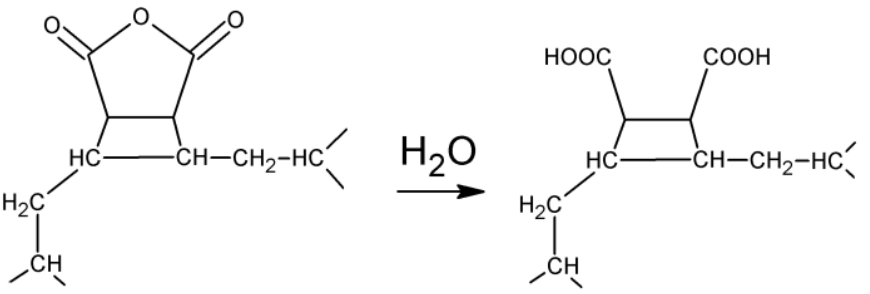




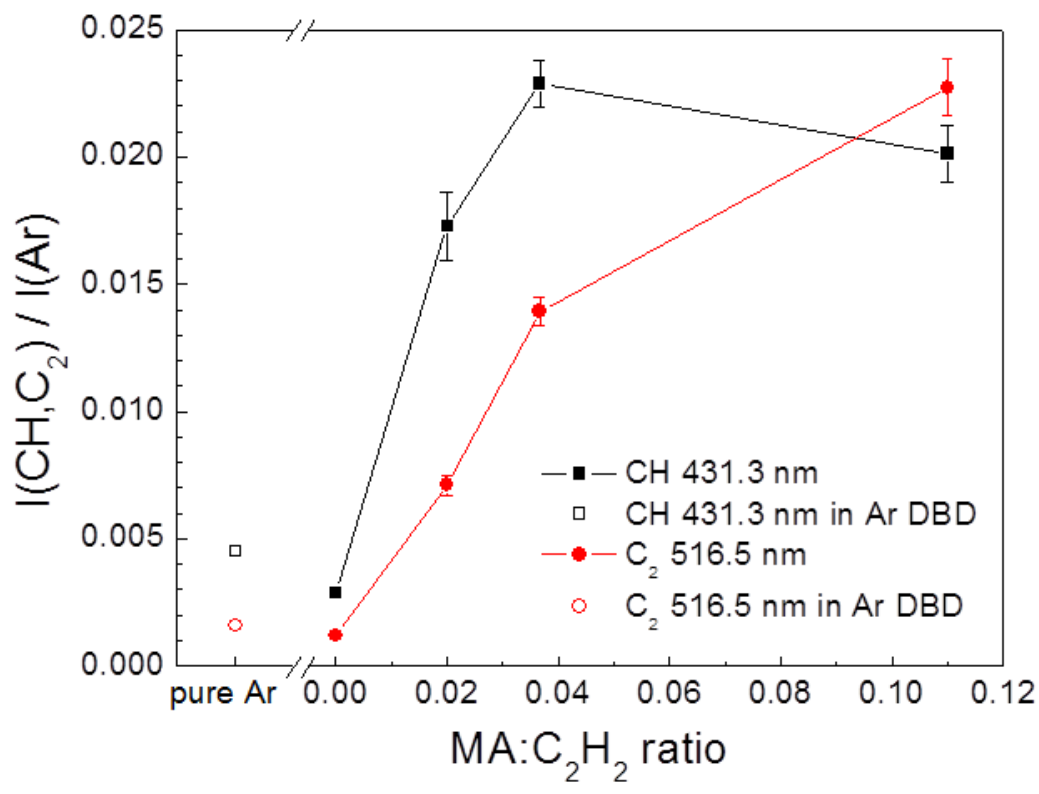



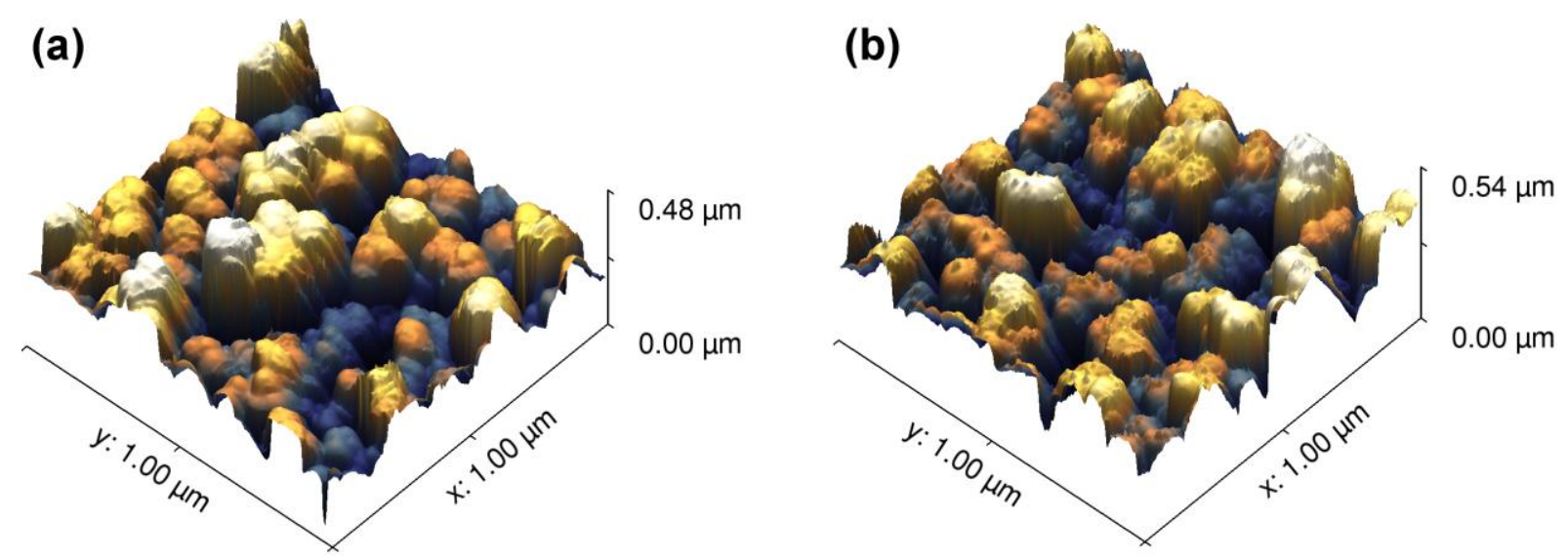

(c)
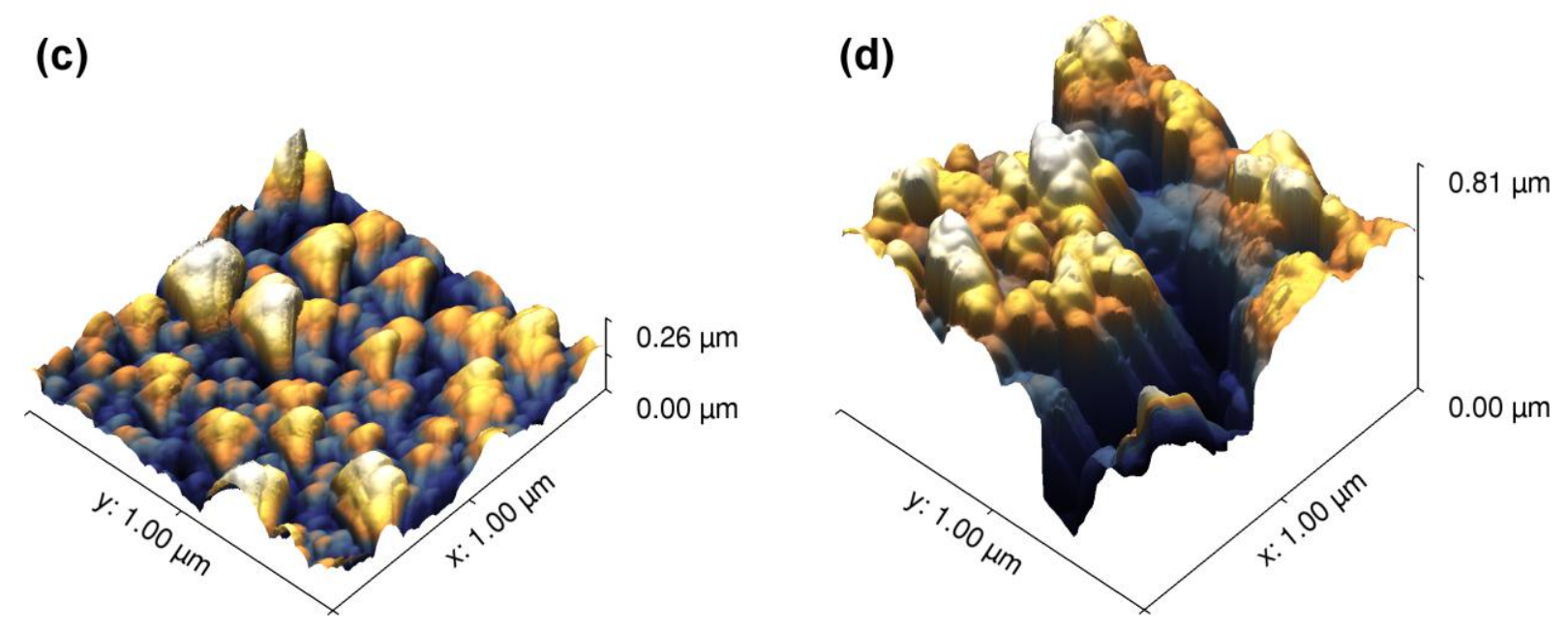


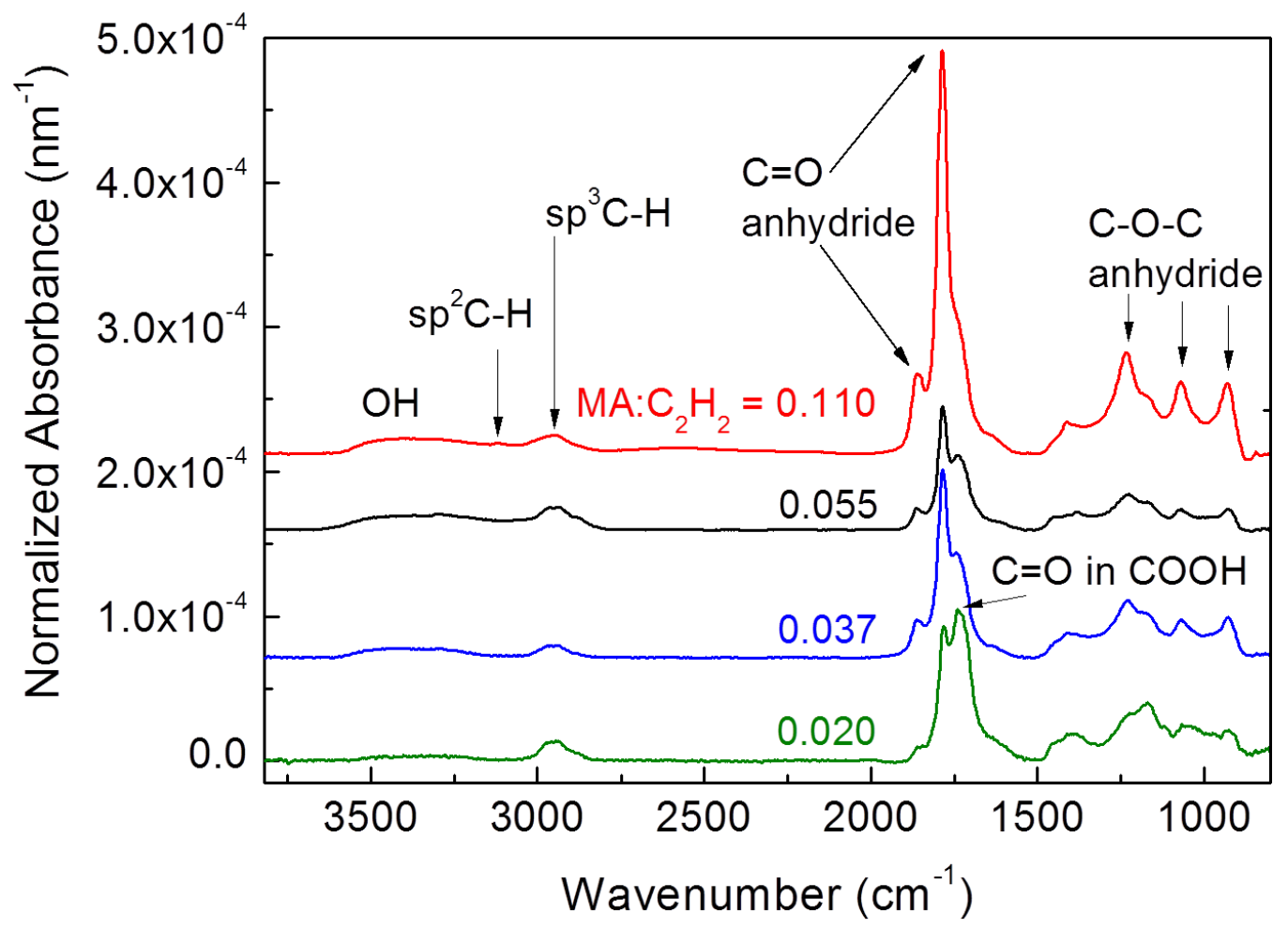




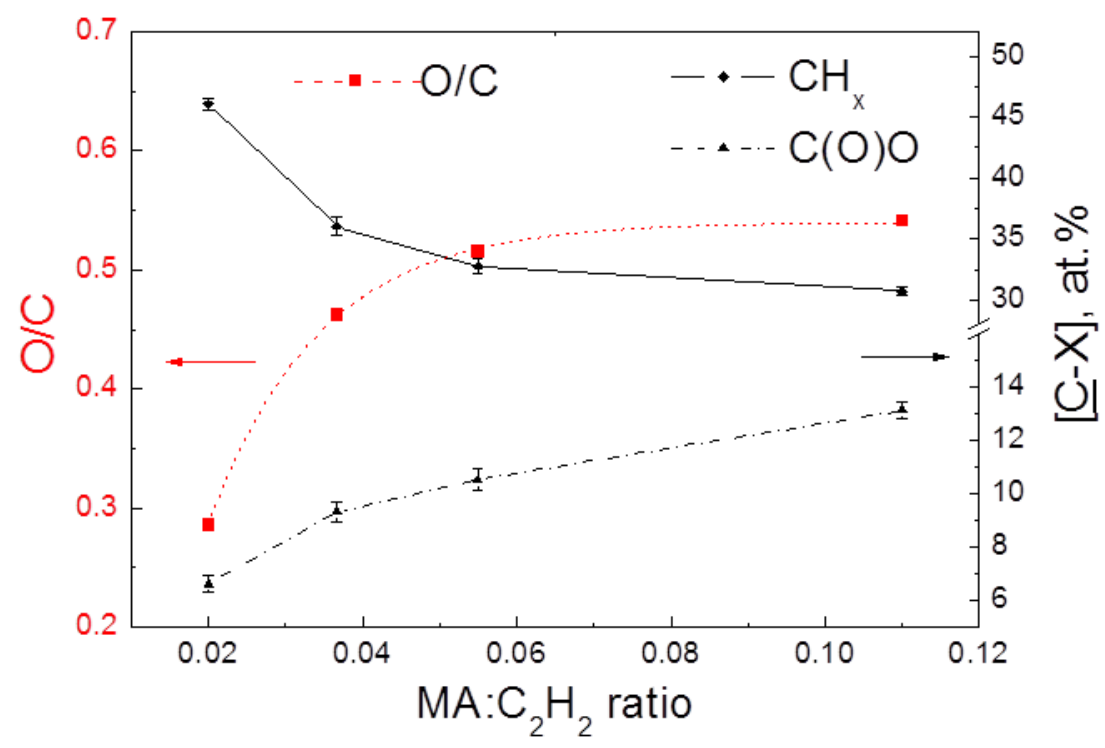




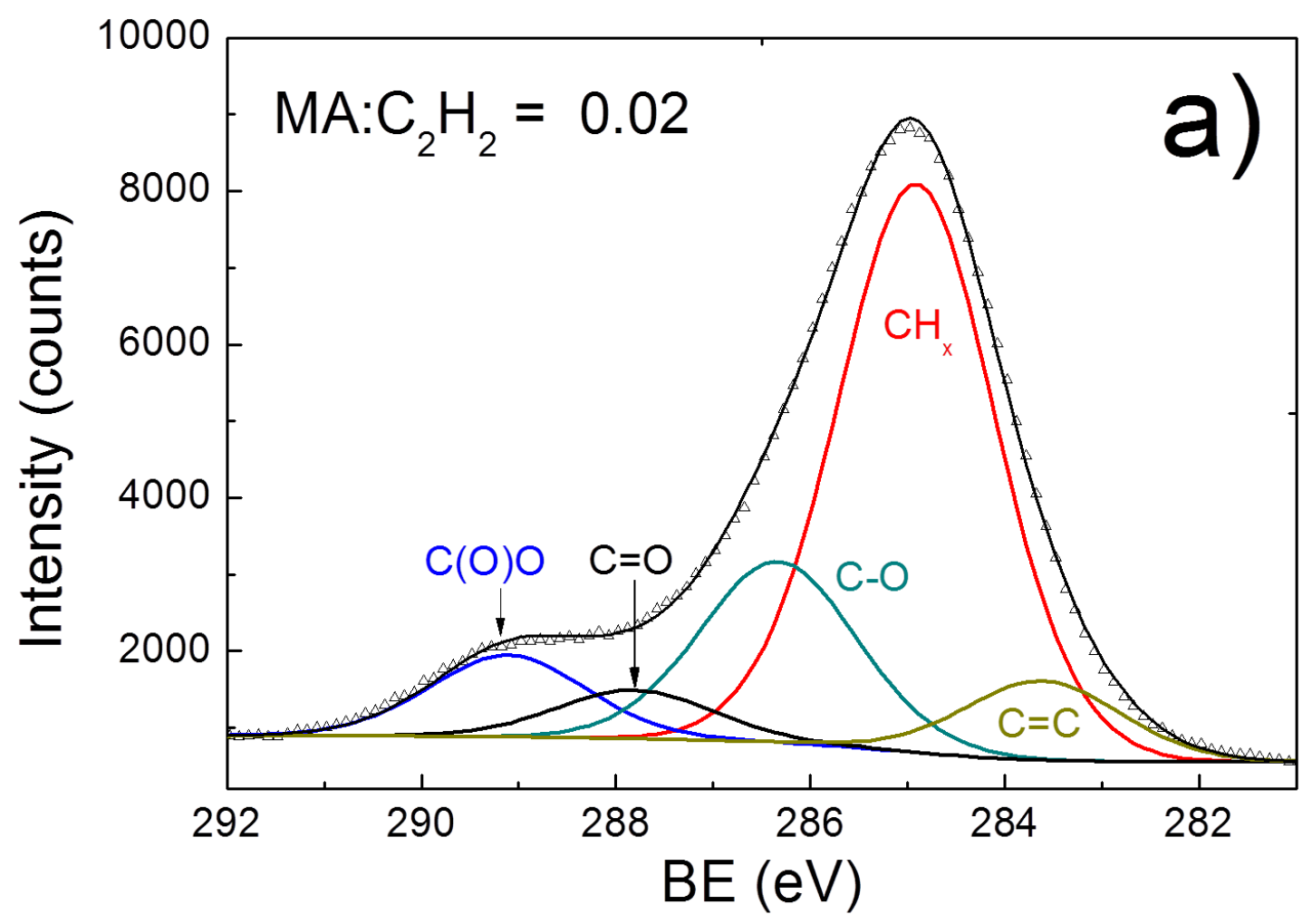




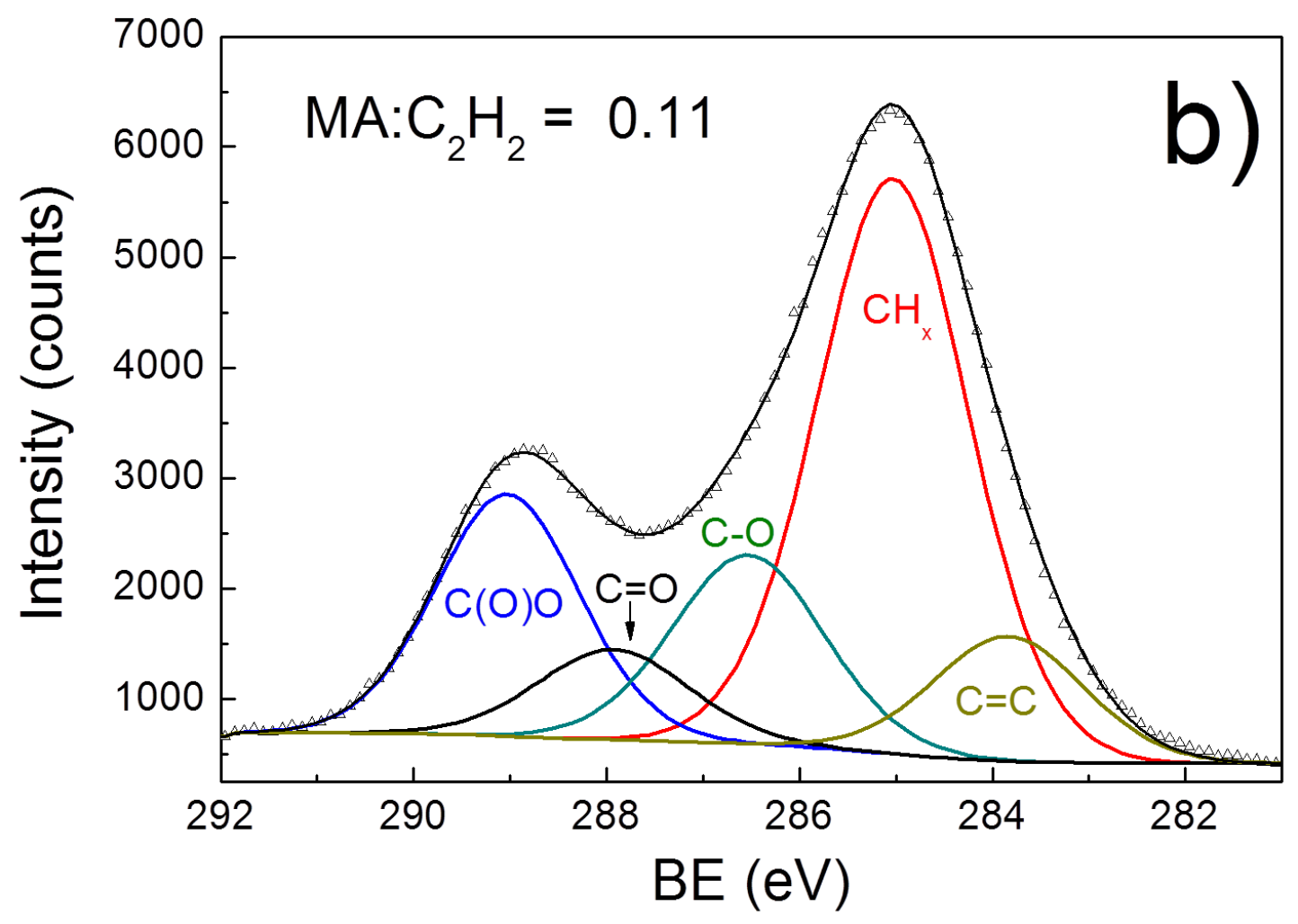




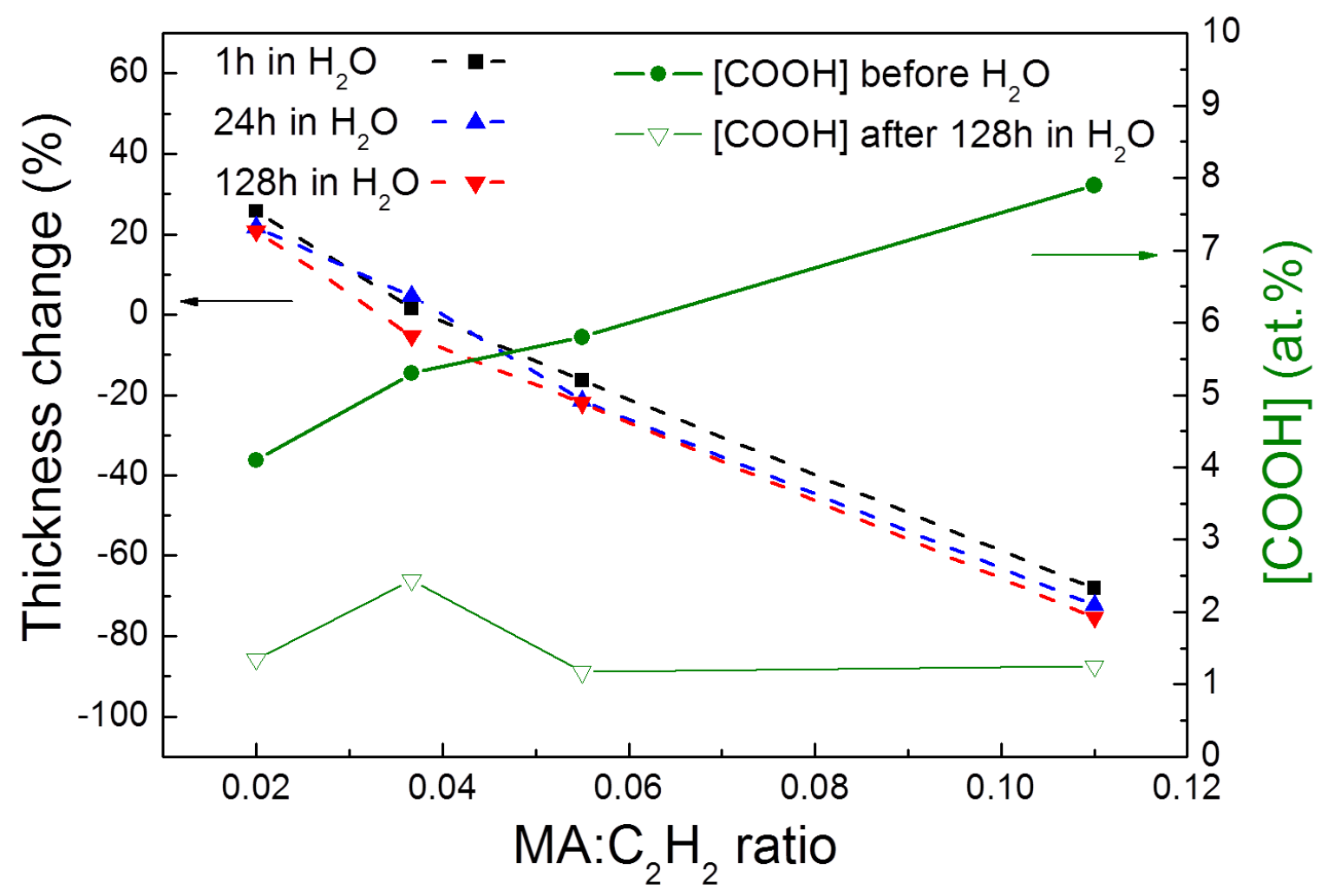



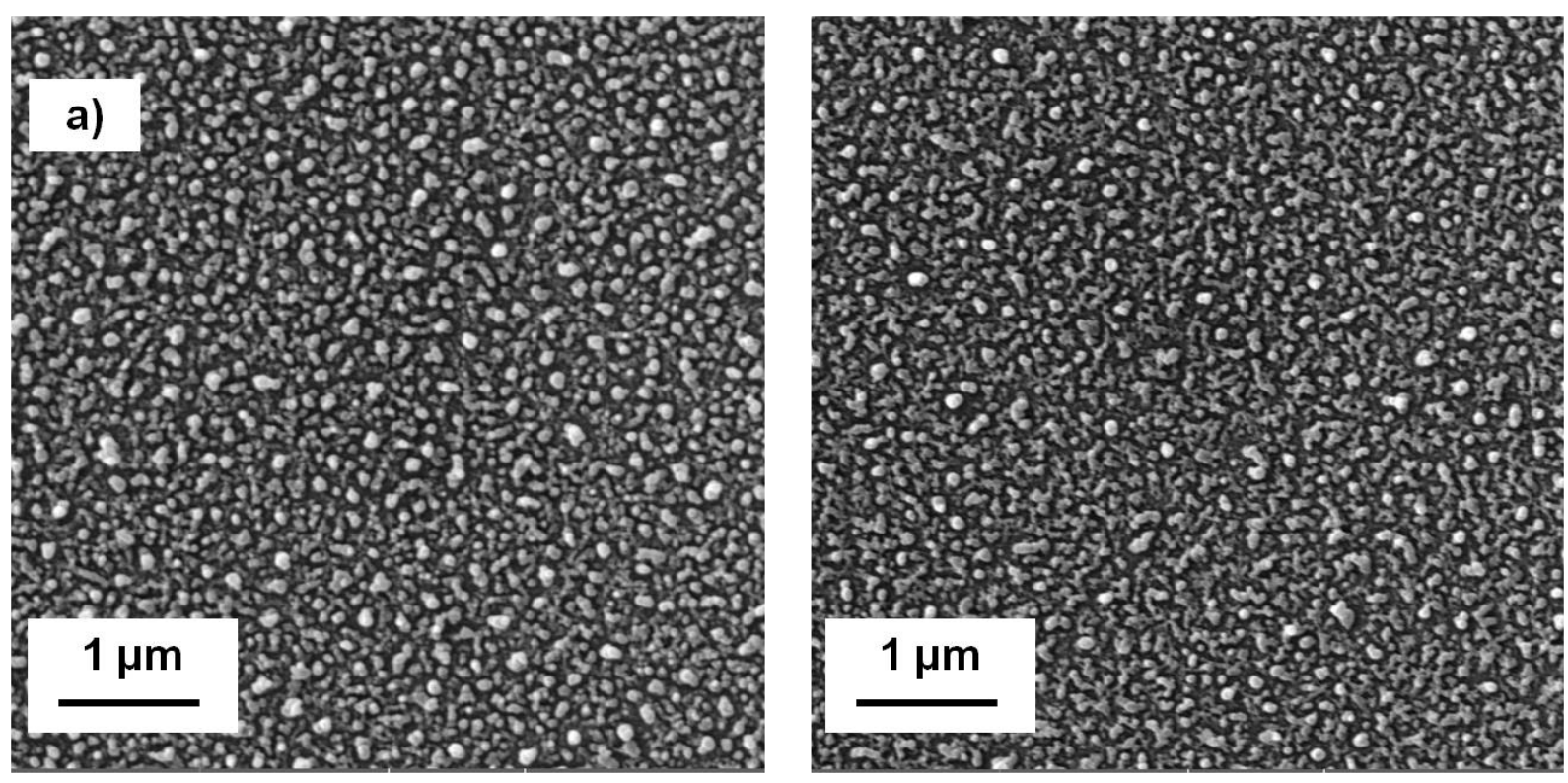

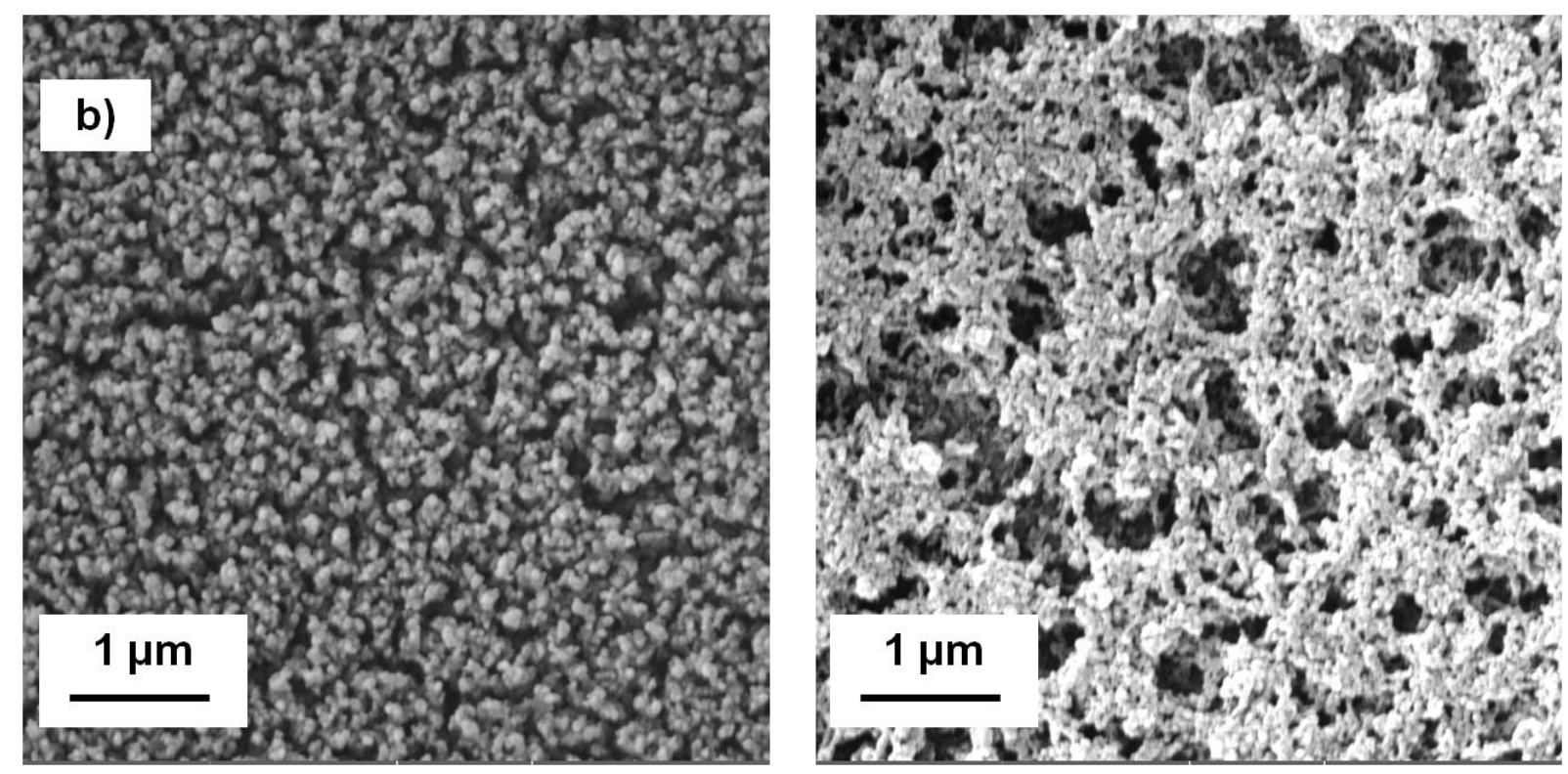

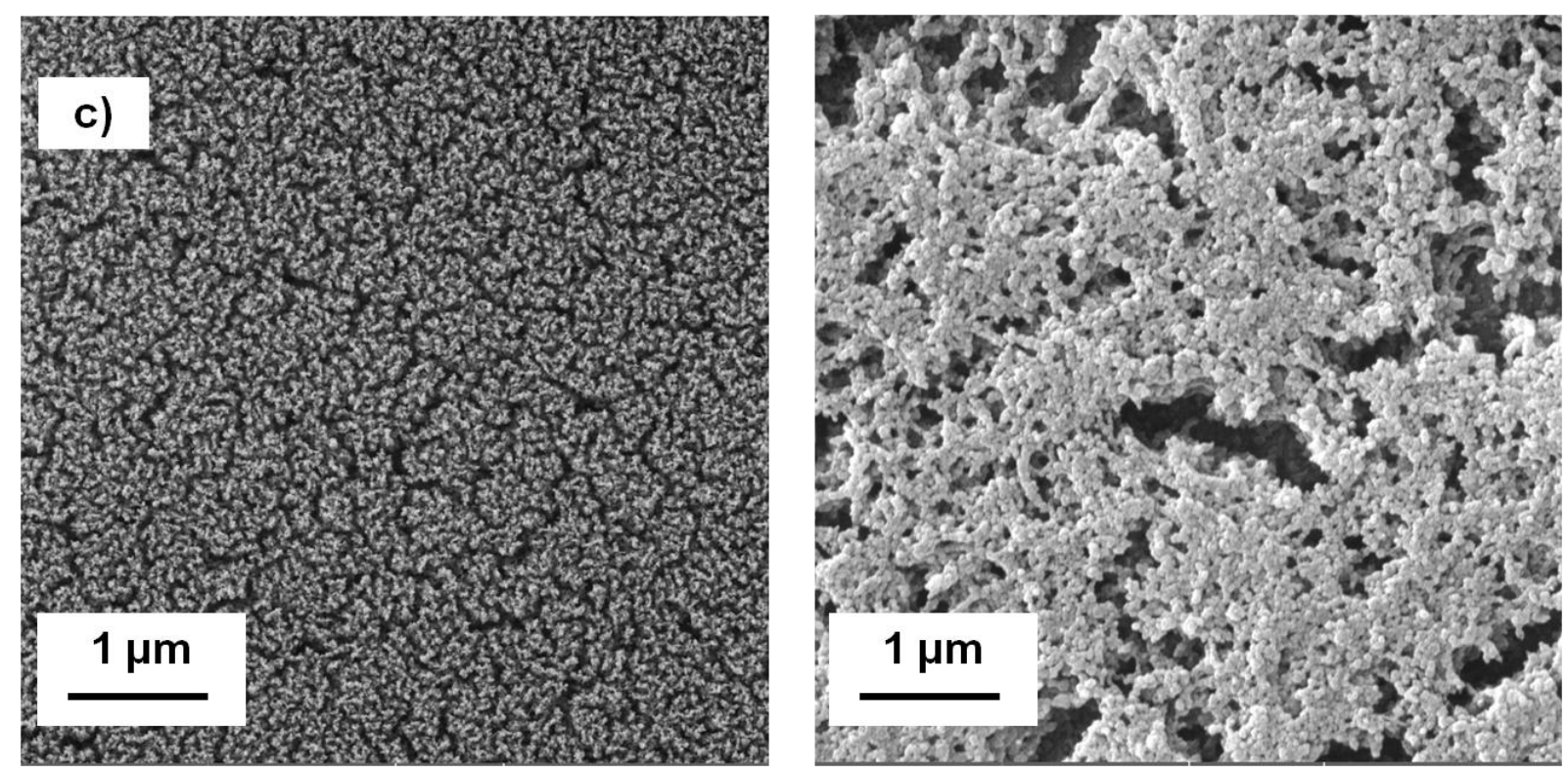


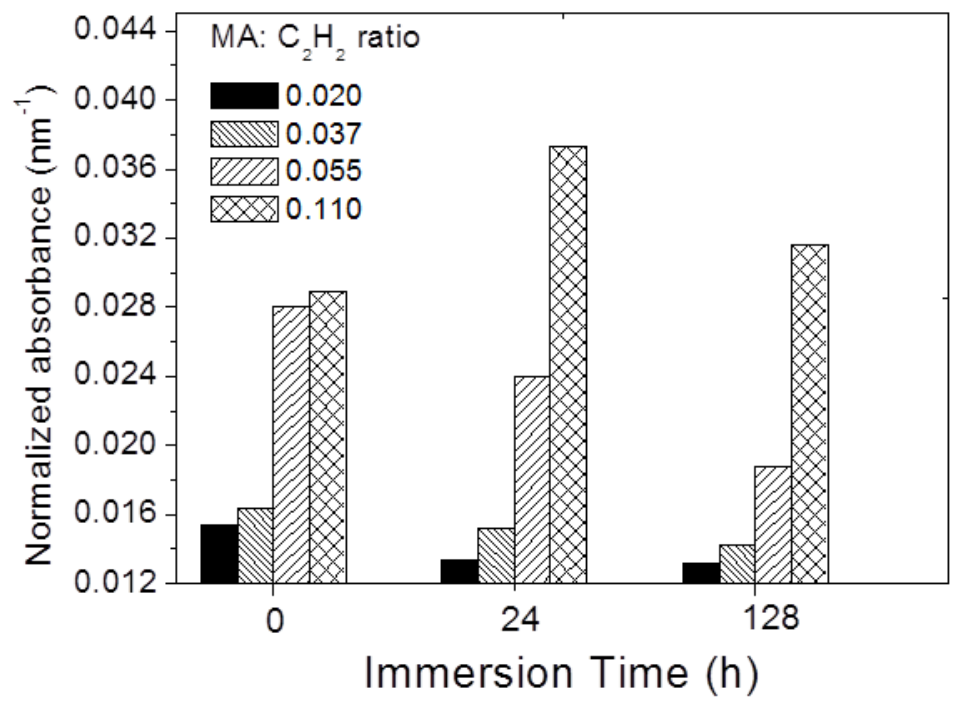




\section{Table}

Table 1: Varied deposition parameters (flow rate of Ar through bubbler - QAr-MA, flow rate of MA - $\mathrm{Q}_{\mathrm{MA}}$, flow rate of $\mathrm{C}_{2} \mathrm{H}_{2}-\mathrm{Q}_{\mathrm{C}_{2} \mathrm{H}_{2}}$ and deposition time), film thickness, surface roughness $\sigma$ and autocorrelation length $\mathrm{T}$.

\begin{tabular}{|l|l|l|l|l|l|l|l|l|}
\hline MA: $\mathrm{C}_{2} \mathrm{H}_{2}$ & $\begin{array}{l}\mathrm{Q}_{\mathrm{Ar}} \\
\text { ratio }\end{array}$ & $\begin{array}{l}\mathrm{Q}_{\text {Ar-MA }} \\
(\mathrm{slm})\end{array}$ & $\begin{array}{l}\mathrm{Q}_{\mathrm{MA}} \\
(\mathrm{s} l \mathrm{scm})\end{array}$ & $\begin{array}{l}\mathrm{Q}_{\mathrm{C}_{2} \mathrm{H}_{2}} \\
(\mathrm{sccm})\end{array}$ & $\begin{array}{l}\text { dep. time } \\
(\mathrm{min})\end{array}$ & $\begin{array}{l}\text { thickness } \\
(\mathrm{nm})\end{array}$ & $\sigma$ & $\mathrm{T}$ \\
\hline 0.020 & 1.25 & 0.25 & 0.06 & 3 & 10 & 687 & 70 & 65 \\
\hline 0.037 & 1.0 & 0.5 & 0.11 & 3 & 10 & 544 & 80 & 65 \\
\hline 0.055 & 1.0 & 0.5 & 0.11 & 2 & 10 & 196 & 49 & 62 \\
\hline 0.110 & 0 & 1.5 & 0.33 & 3 & 5 & $417 *$ & 39 & 64 \\
\hline 0.110 & 0 & 1.5 & 0.33 & 3 & 10 & 938 & 133 & 113 \\
\hline
\end{tabular}

* this PPL was used only for the AFM analysis in order to characterize morphology at a similar thickness. 


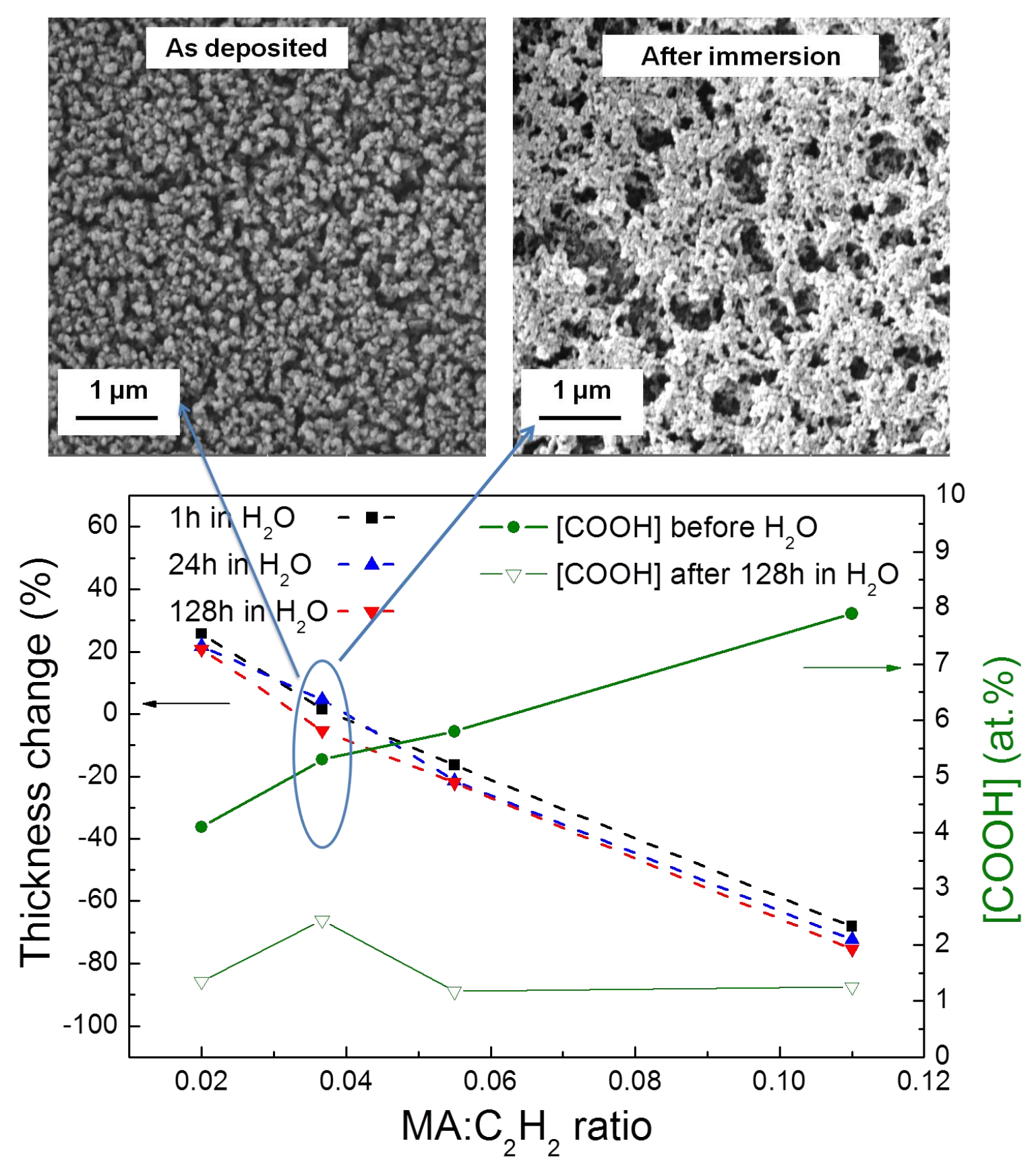

